TI 1997-081/III

Tinbergen Institute Discussion Paper
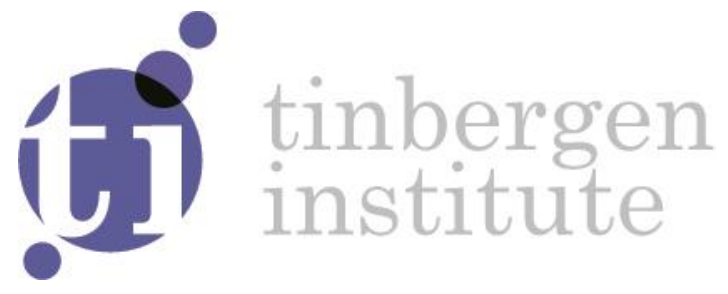

\title{
Equilibrium Search with Continuous Productivity Dispersion: Theory and Non-Parametric Estimation
}

\section{Revision: August 1998}

\author{
Christian Bontemps ${ }^{1}$ \\ Jean-Marc Robin² \\ Gerard J. van den Berg 3
}

\footnotetext{
1 Toulouse School of Economics

2 École Normale Supérieure (ENS) - Laboratoire d'Economie Theorique et Appliquee (LEA); National Institute of Statistics and Economic Studies (INSEE) - Center for Research in Economics and Statistics (CREST); National Institute for Agricultural Research (INRA); Centre for Economic Policy Research (CEPR); IZA Institute of Labor Economics ${ }^{3} \mathrm{VU}$ University Amsterdam - Department of Economics; Centre for Economic Policy Research (CEPR); IZA Institute of Labor Economics; Tinbergen Institute
} 
Tinbergen Institute is the graduate school and research institute in economics of Erasmus University Rotterdam, the University of Amsterdam and VU University Amsterdam.

Contact: discussionpapers@tinbergen.nl

More TI discussion papers can be downloaded at http://www.tinbergen.nl

Tinbergen Institute has two locations:

Tinbergen Institute Amsterdam

Gustav Mahlerplein 117

1082 MS Amsterdam

The Netherlands

Tel.: +31(0)205984580

Tinbergen Institute Rotterdam

Burg. Oudlaan 50

3062 PA Rotterdam

The Netherlands

Tel.: +31(0)10408 8900 


\title{
Equilibrium Search with Continuous Productivity Dispersion: Theory and Non-Parametric Estimation
}

\section{Christian Bontemps*, Jean-Marc Robin** and Gerard J. van den Berg ${ }^{* * *}$}

\author{
Working Paper 98-07 \\ August 1998
}

\author{
JEL classifications: J6, J3, D83, C51
}

Keywords: Labor market equilibrium, job mobility, wages, productivity, monopsony power

\begin{abstract}
In this paper we theoretically and empirically analyze equilibrium search models of the labor market. The Burdett-Mortensen equilibrium search model is generalized by allowing for continuous distributions of firm productivity types within a given labor market. We characterize equilibrium and derive expressions for the endogenous equilibrium wage distributions. We then characterize the full set of wage (offer) distributions that can in principle be generated by the model. We develop a structural nonparametric estimation method for the productivity distribution. We estimate the model using French longitudinal survey data on labor supply, and we compare the results on the relation between productivities and wages to those obtained using a French panel dataset of firms. The results are informative on the degree to which firms exploit search frictions.
\end{abstract}

\section{Acknowledgement}

We are grateful to INSEE for providing the data and to the French Commissariat Général au Plan for financing this research. Gerard J. van den Berg acknowledges the Royal Netherlands Academy of Arts and Sciences for financial support. We have greatly benefited from comments by and discussions with Zvi Eckstein, Audra Bowlus, Guy Laroque, Francis Kramarz, Jim Albrecht and Sebastién Roux. We are grateful to David Margolis and Francis Kramarz for providing the firm data to us and for comments. Also thanks to Menno Pradhan for computational assistance and suggestions.

A preliminary version of this paper was distributed among participants of a conference on equilibrium search in Sandbjerg in June 1995 under the title "Equilibrium search and on-the-job search".

\section{Addresses}

Corresponding author: Gerard J. van den Berg, Department of Economics, Free University Amsterdam, De Boelelaan 1105, NL-1081 HV Amsterdam. The Netherlands.

E-mail: gberg@econ.vu.nl. 


\section{Introduction}

It is well-known that the presence of informational frictions on the labor market gives employers a certain monopsony power. Basically, firms can maintain a positive workforce if they pay wages that are strictly smaller than the productivity level of the workers, because it takes time for the workers to find a better paying job. Indeed, if workers for some reason cannot search on the job and if they are homogeneous, then it is optimal for wage-setting firms to offer a wage equal to the common reservation wage of the unemployed. Offering a higher wage would not increase its workforce. The resulting equilibrium is then the same as in the model in which one firm is monopolist in the labor market: all firms offer a wage equal to the value of leisure (this is the so-called Diamond solution, named after Diamond (1971) who was the first to acknowledge this).

Burdett and Mortensen (1998) generalize the Diamond (1971) model by allowing workers to search on the job at a given rate. Working individuals only change jobs if the wage offer exceeds their current wage. A firm that sets a high wage is thus able to attract workers from firms offering lower wages. However, firms still have a certain monopsony power, because workers cannot move instantaneously to the firm paying the highest wage in the market. If individuals work at different wages then, from the point of view of an employer, the labor supply curve is upward sloping, and there is a trade-off between the wage and the labor supply faced by the firm. In equilibrium, all firms obviously have the same profit level, but this can be attained by paying a low wage (thus attracting few workers) as well as by paying a high wage (attracting many workers). As a result, wage offers are dispersed in equilibrium. The monopsony power of a given firm, as measured by the fraction of labor productivity not paid to the worker, thus also differs across firms.

The average wage and the average monopsony power decrease in the degree of search frictions faced by employed workers. In the extreme case of no on-the-job search (maximum friction), the monopoly wage applies, whereas in the extreme case of instantaneous arrival of job offers (no friction), the wage is competitive. The degree of equilibrium wage dispersion is also directly related to the degree of search frictions faced by employed workers. In the general (i.e., non-polar) case, wages are dispersed between the two wage extremes.

The above-mentioned papers do not allow for firms to have different technologies. In particular, it is assumed that the productivity of labor is the same across firms. This means that the level and the dispersion of the wage and the monopsony power are fully determined by the degree of search frictions and the common values of productivity and leisure. In reality, firms employ different production technologies. As a result, workers are more productive in one firm than in another. This can be expected to have implications for the distribution of wages. More productive firms may offer higher wages than less productive firms, so wage dispersion may be larger than in a homogeneous market. The mapping from productivities to wage offers can be expected to depend on the degree of search frictions, and the latter can be influenced by policy measures aimed at improving the flow of information on vacancies to job seekers. 
Productivity dispersion also affects the distribution of monopsony power across firms. It is likely that this favors high-productivity firms relative to low-productivity firms, in the sense that the wages set by the latter necessarily lie in the narrow interval between the value of leisure and the low productivity level itself. As a result, highproductivity firms may enjoy very high profits on labor. To the extent in which this can not be attributed to the use of other production factors or investment in research, this may be a reason to tax profits.

In the present paper we investigate these issues by constructing and estimating an equilibrium search model that allows for a continuous distribution of firms' productivities. We restrict attention to continuous distributions for two reasons. First, qualitative features of the equilibrium solution are more transparent in the continuous case. Secondly, our model allows a feasible nonparametric estimation method for the productivity distribution. We provide a comprehensive analysis of this equilibrium search model. We prove existence of the equilibrium, and we derive expressions for the distributions of wages and durations in terms of the primitives of the model.

An important part of the theoretical analysis concerns the derivation of qualitative features of the equilibrium solutions. These are important for addressing the extent to which the model is able to explain observed behavior. For example, we fully characterize the set of wage distributions that can be generated by the model. This can be used to construct tests of the model. Other qualitative results relate the shape of the tail of the productivity distribution to the shape of the tail of the wage offer distribution. In addition to this, we allow for mandatory minimum wages in the model and we derive necessary and sufficient conditions for the wage distributions to display a peak at the mandatory minimum wage.

The paper provides a rather extensive empirical analysis of the model. First, we structurally estimate the equilibrium search model, using French panel survey data on individuals in the labor force. For this, we develop and apply a nonparametric structural estimation method for the productivity distribution, based on an inversion from wages to productivities. The empirical analysis is stratified by industry. The estimation results are used to estimate the wage as a function of the productivity level, and to estimate the degree of monopsony power of firms.

We then proceed by confronting these results to rather unique (French) firm data. This dataset records amongst other things the value-added per worker and mean wage at the firm level. It turns out that there is a qualitative agreement between what the theoretical model predicts and the actual relationship between the value-added per worker and the wage. In addition, there exist similarities between the estimation results from the worker data and the corresponding relations in the firm data.

Our empirical analysis with worker data contributes to the recently expanding literature in which existing equilibrium search models are estimated. This empirical literature emerged in response to the obvious disadvantages of partial analyses. ${ }^{1}$ Note

\footnotetext{
${ }^{1}$ It should be noted from the outset that we restrict attention to models in which firms set wages, at the exclusion of so-called "matching" models in which wages are the result of a bargaining process
} 
that for an equilibrium search model to have empirical contents, it must be able to generate wage dispersion for searching individuals. This rules out the Diamond (1971) model. Instead, firms should face upward sloping labor supply curves, or, in other words, potential workers should differ in their reservation wage values, so that there is an advantage in offering high wages.

Eckstein and Wolpin (1990) pioneered the empirical analysis of equilibrium search models by estimating a model in which unemployed workers are heterogeneous in terms of their value of leisure and workers do not search on the job. (This model is developed by MacMinn (1980) and Albrecht and Axell (1984).) They also allow firms to have different labor productivities. This model gives an acceptable fit to individual unemployment duration data, but the fit to the wage data is not satisfactory. The latter is due to the fact that each point of support of the wage offer distribution necessarily equals the reservation wage of an unemployed worker type (see also the discussion by Eckstein and Wolpin (1990) of their results).

The second approach in the empirical analysis of equilibrium search models is based on the model by Burdett and Mortensen (1998) (see also Mortensen (1990), and theoretical extensions in Wernerfelt (1988), Ridder and Van den Berg (1997) and Mortensen and Vishwanath (1994).) This model has a number of attractive features. Most importantly, it allows for job-to-job transitions, which are important in their own right as well as for understanding search behavior, wage growth, and the importance of wage setting for maintaining the workforce of a firm. Note that the possibility of on-the-job search changes the optimal search strategy of unemployed job seekers. The equilibrium solution satisfies a number of stylized facts of the labor market, particularly concerning the relation between job durations, wages, and the size of firms. ${ }^{2}$ For example, larger firms offer higher wages. Also, in general, wages exceed the reservation wage of the unemployed, contrary to the model estimated by Eckstein and Wolpin (1990). However, the actual solutions for the equilibrium wage offer distribution and the distribution of wages in a cross-section of workers have increasing densities. This implication is at odds with the data. This means that the shapes of the wage distributions are not explained by the model.

Van den Berg and Ridder (1998) and Koning, Ridder and Van den Berg (1995) estimate versions of the Burdett and Mortensen (1998) model in which the labor market is considered to consist of a large number of segments. Each segment is a separate labor market of its own, and workers and firms in a particular segment are homogeneous. The segments are defined by observed characteristics like occupation as well as by unobserved characteristics. All structural parameters are allowed to vary across segments (this is called between-market heterogeneity, contrary to the model in the present paper, which allows for within-market heterogeneity). As a result, the data provide observations from mixtures of homogeneous markets. The estimated models provide an accurate fit to data on cross-sectional wages. However, it is obviously not

(see e.g. Pissarides (1990)).

${ }^{2}$ See also Kiefer and Neumann (1993) and Ridder and Van den Berg (1997). 
very realistic to assume that all firms in a given segment have identical productivity. Moreover, within a single segment, most of the estimated probability mass of the wage distribution is usually confined to narrow interval, which implies that the sequence of wages that an individual earns in a sequence of jobs lies in a very narrow interval.

The theoretical article by Mortensen (1990) analyzes equilibrium search with heterogeneity in firms' productivities and workers' opportunity costs of employment, assuming that the heterogeneity distributions are discrete. ${ }^{3}$ He derives expressions for the equilibrium solution and shows that equilibrium exists. Bowlus, Kiefer and Neumann (1995) develop and apply an estimation method for the Mortensen (1990) model, allowing for discrete heterogeneity of firms' productivities and assuming homogeneity of workers. Due to the highly nonlinear nature of the model, this method becomes rapidly so computationally intensive that it is hardly possible to estimate a model with more than a few points of support for the distribution of productivities, while the fit to the wage data density of a model with a few points of support is not very satisfactory. Moreover, the likelihood is not well behaved and numerical algorithms which do not require differentiation of the optimization criterion are needed. For our purposes it is important to stress that a continuous productivity distribution is able to mimic a discrete distribution. A huge peak in the density of the continuous distribution reflects the presence of a large fraction of firms with about the same productivity value.

In this paper, we do not allow for heterogeneity by nature among individuals. First of all, the empirical analysis by Eckstein and Wolpin (1990) shows that such heterogeneity can only explain a small fraction of wage variation. Secondly, and more importantly, it is useful to generalize equilibrium search models step by step, and we feel that the extensions that we consider in the present paper generate a large number of interesting new results.

The outline of the paper is as follows. Section 2 presents the general model in which the productivity distribution is not yet restricted to be continuous. In Section 3 we examine the model with continuous productivity distributions. In Section 4 we discuss the data used to estimate the model, we derive the likelihood function, and we develop and apply a nonparametric structural estimation method. Section 4 also presents the results for the firm data. Conclusions are in Section 5. To avoid lengthy technical elaborations, we have relegated a few technical details and proofs to a working paper version of this paper (Bontemps, Robin and Van den Berg (1997), henceforth $\mathrm{BRVdB}$ ), which is available upon request.

\footnotetext{
${ }^{3}$ See Reinganum (1979) for another study that can be regarded as a forerunner of the present paper. That paper is concerned with sequential consumer search with elastic demand curves and heterogeneous production costs.
} 


\section{Equilibrium Search with Identical Workers and Heterogenous Firms}

Because the model version in which workers and firms are homogeneous has been presented numerous times before (see the references in the introduction), most of the present exposition can be brief.

\subsection{Worker Behavior}

Workers seek to maximize the expected steady-state discounted (at rate $\rho$ ) future income. The opportunity cost of employment is denoted by $b$ and is assumed to be constant across individuals. When unemployed, job offers accrue at the constant rate $\lambda_{0}$. When employed, job offers accrue at the constant rate $\lambda_{1}$. Whenever an offer arrives, the decision has to be made whether to accept it or to reject it and search further for a better offer. Layoffs accrue at the constant rate $\delta$. The distribution of wage offers $F$ is independent of the current state of the job searcher (employed or unemployed). Let $\operatorname{supp}(F)$ denote the support of $F$. We denote $\underline{w}=\inf [\operatorname{supp}(F)]$ and $\bar{w}=\sup [\operatorname{supp}(F)]$. Note that $\bar{w}$ can be infinite. We also allow for possibility of a legal minimum wage (call it $w_{\min }$; if there is no legal minimum wage then take $w_{\min }=0$ ). Necessarily then, $\underline{w} \geq w_{\min }$

Proposition 1 (Mortensen and Neumann (1988).) The optimal strategy when unemployed is to accept any wage offer $w$ greater or equal to $\phi$, where $\phi$, the reservation wage, is implicitly defined as

$$
\begin{aligned}
\phi & =b+\left(\lambda_{0}-\lambda_{1}\right) \int_{\phi}^{\bar{w}} \frac{\bar{F}\left(x^{-}\right)}{\rho+\delta+\lambda_{1} \bar{F}\left(x^{-}\right)} d x \\
& =b+\left(\kappa_{0}-\kappa_{1}\right) \int_{\phi}^{\bar{w}} \frac{\bar{F}\left(x^{-}\right)}{\beta+1+\kappa_{1} \bar{F}\left(x^{-}\right)} d x,
\end{aligned}
$$

with $\kappa_{0}=\lambda_{0} / \delta, \kappa_{1}=\lambda_{1} / \delta$ and $\beta=\rho / \delta$.

The optimal strategy when employed is to accept any wage offer strictly greater than the present wage contract.

Above, we use notation $\bar{F}(w)=1-F(w)$, and we take the convention that $F(w)$ denotes the probability that the wage offer is smaller than or equal to $w$. Moreover $\bar{F}\left(x^{-}\right)$is a notation for $\lim _{\varepsilon \downarrow 0} \bar{F}(x-\varepsilon)$. We have extended Mortensen and Neumann's formula to include the case of wage offer distributions with mass points. This explains why $\bar{F}\left(x^{-}\right)$appears in formula (1) instead of $\bar{F}(x)$. (Proof available on request.) Below we make an assumption ensuring that $E_{F}(w)<\infty$. As a result, $\phi$ above is finite.

Note that at this stage it is already clear that firms do not offer a wage $w<\phi$, because they would not hire anybody. A firm with zero employment is said inactive and not participating to the market. Thus, $\underline{w} \geq \phi$. 


\subsection{Steady-State Equilibrium Worker Flows}

The measure of individual labor force participants is $M$ and the measure of unemployed is $U$. The measure of active firms is $N$. Let $G(w)$ be the fraction of individuals with a wage lower than or equal to $w$ in the stock of employed workers. Consider all individuals working at a wage lower than or equal to $w$. In a steady-state demographic equilibrium, the flow of layoffs in an interval $(t, t+d t]$ is $\delta(M-U) G(w) d t$. Moreover, the measure of workers moving to jobs paying more than $w$ is $\lambda_{1} \bar{F}(w)(M-U) G(w) d t$, while the measure of unemployed individuals accepting a wage smaller than or equal to $w$ is $\lambda_{0} F(w) U d t$, if $w \geq \phi$. Recall that $F\left(\phi^{-}\right)=0$.

At the equilibrium, one must have equal flows in and out of the stock of workers employed at a wage lower than $w$. Hence:

$$
\lambda_{0} U F(w)=\left[\delta+\lambda_{1} \bar{F}(w)\right](M-U) G(w)
$$

if $w \geq \phi$, and flows are zero if $w<\phi$.

For $w=\bar{w}$, equation (4) implies that

$$
\lambda_{0} U=\delta(M-U)
$$

or

$$
u=\frac{1}{1+\kappa_{0}}
$$

where $u=U / M$ is the unemployment rate. It follows that

Proposition 2 In a steady-state demographic equilibrium, one must have that:

$$
u=\frac{1}{1+\kappa_{0}}
$$

and

$$
1+\kappa_{1} G(w)=\frac{1+\kappa_{1}}{1+\kappa_{1} \bar{F}(w)} .
$$

The latter equation is the (simple) structural relationship, imposed by the steadystate demographic equilibrium, between the distribution $G$ of actual earnings in the population of employees and the distribution $F$ of wage offers.

Note that the model tells nothing about the origin of friction parameters $\kappa_{0}$ and $\kappa_{1}$. In this sense, they are exogenous. However, they can be thought to be related to $M$ and $N$. Although $M$ is exogenously given in the present model, this is not necessarily the case in an extended version of the model incorporating worker heterogeneity. In this extended model, workers with exceptionally high reservation wages may never participate at the market because the maximum wage offer is not sufficiently large. The number of active firms $N$ shares the same feature: only those firms whose productivity is greater than any legal minimum wage or minimum reservation wage can survive. An ad hoc way of making $\kappa_{0}$ and $\kappa_{1}$ endogenous would be to make them functions of a 
tension indicator like $N / M$ for example. It is indeed reasonable to assume that the more numerous firms are compared to workers, the greater the instantaneous probability for a searching worker to receive a job offer. However, such a model extension is non-trivial, and throughout this paper we maintain the assumption that $\lambda_{0}, \lambda_{1}$ and $\delta$ are given constants.

\subsection{Firm Behavior}

$F(w)$ is the probability that a worker receives a job offer with a wage less than $w$. A now standard assumption in job-search equilibrium models is to assume that workers draw job offers by randomly picking firms using a uniform sampling scheme. If a given firm, whatever its size, offers only one wage (which is the maintained assumption in this paper), and if all firms want to expand by posting vacancies (which will be shown to be true below), then $N F(w)$ must be the measure of firms offering a wage less than $w$. We also make this assumption here. Since $(M-U) G(w)$ is the measure of employed workers earning less than $w$, it follows that the steady-state number of workers per firm paying $w$ is then the Radon-Nykodin density of distribution $(M-U) G$ with respect to $N F$ :

$$
\begin{aligned}
l(w) & =\frac{M-U}{N} \frac{d G(w)}{d F(w)} \\
& =\frac{M-U}{N} \frac{1+\kappa_{1}}{\left[1+\kappa_{1} \bar{F}(w)\right]\left[1+\kappa_{1} \bar{F}\left(w^{-}\right)\right]} .
\end{aligned}
$$

Note that if $\lambda_{1}=0$ then $l(w)=\frac{M-U}{N}$, meaning that all employment is uniformly distributed across firms. In general, $l(w)$ is an increasing function of $w$ on the support of $F$, whatever the shape of the equilibrium wage distribution. This is due to the fact that high-wage firms attract more workers.

Firms may differ by their labor productivity $p$. The distribution function of $p$ is $\Gamma_{0}(p)$, with $\underline{p}_{0} \geq 0$ as the infimum point of its support and $\bar{p}$ the supremum. (It will become clear later on why we do not attach a subscript zero to $\bar{p}$.) We assume that $p$ has a finite mean, i.e. $E_{\Gamma_{0}}(p)<\infty$. $\Gamma_{0}$ is a structural determinant of the model. It describes the distribution of $p$ that prevails if all potentially active firms have entered the market.

Consider a firm with a flow $p$ of marginal revenue generated by employing a worker. We assume that $p$ does not depend on the number of workers at the firm, and consequently we will refer to this firm as a firm of type $p$ and to $p$ as the (labor) productivity of this firm. We assume that the firm seeks to maximize its steady-state profit flow

$$
\pi(p, w)=(p-w) l(w)
$$

where $l(w)$ is the size of the labor force that it can expect to employ if all workers behave so as to maximize their expected wealth and if all other firms' wage offers are distributed according to the distribution $F$. 
A firm does not offer a wage exceeding its revenue product $p$ because profits would be negative. Moreover, any wage offer is greater than both the workers' reservation wage $\phi$ and the legal minimum wage $w_{\min }$. Indeed, $\underline{w}=\max \left\{\phi, w_{\min }\right\}$, as is intuitively clear (see Mortensen (1990) and BRVdB).

We shall take $\operatorname{Pr}_{\Gamma_{0}}\left\{p>\max \left\{b, w_{\text {min }}\right\}\right\}>0$, which is a necessary condition to have production. It should be noted that, as long as $\operatorname{Pr}_{\Gamma_{0}}\left\{p>w_{\text {min }}\right\}>0$, increases in the minimum wage do not affect unemployment. If $w_{\min }=\underline{p}$, and $w_{\min }$ increases from $w_{1}$ to $w_{2}$, then firms with $w_{1}<p \leq w_{2}$ go bankrupt and the remaining firms simply become larger (see also Eckstein and Wolpin (1990)). However, if the economy consists of completely separated segments such that in some segments $w_{1}<\bar{p}<w_{2}$ then unemployment in these segments increases to $100 \%$. Alternatively, if the measure of active firms affects $\lambda_{\mathbf{0}}$ then unemployment may be affected as well.

We denote as $\underline{p}$ the infimum productivity of firms which make a non-negative profit and thus are active on the market and as $\Gamma(p)$ the distribution of productivities of active firms:

$$
\Gamma(p)=\left[\Gamma_{0}(p)-\Gamma_{0}(\underline{p})\right] / \bar{\Gamma}_{0}(\underline{p}),
$$

with $p \geq \underline{p}$. It is again intuitively obvious that $\underline{p} \geq \max \left\{\underline{p}_{0}, \phi, w_{\min }\right\}$.

It thus follows that the measure of active firms is endogenous:

$$
N=N_{0} \bar{\Gamma}_{0}(\underline{p})
$$

where $N_{0}$ is the measure of potentially active firms. Note that all active firms are always willing to expand, since the marginal revenue product is constant while the profit flow is positive (for convenience, we abstract from the pathological case in which a positive mass of firms have $\left.p=\max \left\{\phi, w_{\min }\right\}\right)$.

We do not assume from the outset that all firms of same type necessarily have the same strategy. If different wage values yield identical profit, two firms may choose different strategies. An optimal strategy for a firm of type $p$ will thus be a point in a set $K_{p}$ of profit maximizing wages:

$$
K_{p}=\arg \max _{w}\left\{\pi(p, w) \mid \max \left\{\phi, w_{\min }\right\} \leq w \leq p\right\}
$$

with

$$
\pi(p, w)=A \frac{p-w}{\left[1+\kappa_{1} \bar{F}(w)\right]\left[1+\kappa_{1} \bar{F}\left(w^{-}\right)\right]},
$$

where

$$
A=\left(1+\kappa_{1}\right) \frac{M-U}{N_{0} \bar{\Gamma}_{0}(\underline{p})} .
$$

If on-the-job search is impossible $\left(\kappa_{1}=0\right)$ then obviously the optimal strategy of all firms is to offer a single wage equal to $\max \left(\phi, w_{\text {min }}\right)$, implying that, at the equilibrium, the wage offer distribution is a mass point at $\max \left(b, w_{\min }\right)$ (the Diamond (1971) solution). 
Moreover, if $\kappa_{1}>0$ and if $K_{p}$ is not a singleton, then firms are indifferent between several alternative strategies. We assume that the behavior of all firms of the same type is to (symmetrically) put probabilities on each element of $K_{p}$, and draw a single wage value as their offer to workers before entering the market. From now on we define firms' strategies as these probability distributions. They can be seen as a sort of mixed strategy, although firms always offer the same wage to workers. One could indeed alternatively allow firms to draw a new wage offer for every new worker which contacts them. However, there are many obvious reasons not to consider such possibilities. In particular, they would generate a distribution of wages within firms and thus violate within-firm fairness constraints.

Let $F(. ; p)$ define a strategy for type- $p$ firms. Then, it must be true that

$$
F(\cdot)=\int F(\cdot ; p) d \Gamma(p)
$$

\subsection{Market Equilibrium}

The equilibrium concept we use here is the same as in Diamond (1971) and Mortensen (1990).

Definition 1 A market equilibrium is a triple $(\phi, \underline{p},\{F(\cdot ; p), p \geq \underline{p}\})$ such that

1. the distribution of wage offers in the economy is

$$
F(\cdot)=\int F(\cdot ; p) d \Gamma(p)
$$

2. only firms with productivity $p$ greater than $\underline{p}$ are active and the distribution of their productivities is

$$
\Gamma(p)=\left[\Gamma_{0}(p)-\Gamma_{0}(\underline{p})\right] / \bar{\Gamma}_{0}(\underline{p})
$$

3. $\phi$ is workers' best response to firms' aggregate behavior, i.e.

$$
\phi=b+\left(\kappa_{0}-\kappa_{1}\right) \int_{\phi}^{\bar{w}} \frac{\bar{F}\left(x^{-}\right)}{1+\beta+\kappa_{1} \bar{F}\left(x^{-}\right)} d x
$$

4. the strategies of each type-p firm is to randomly draw a wage from probability distribution $F(\cdot ; p)$ which puts positive probability on the set $K_{p}$ of profit maximizing wages of type-p firms given other firms' and workers' strategies, i.e.

$$
K_{p}=\arg \max _{w}\left\{\pi(p, w) \mid \max \left(\phi, w_{\min }\right) \leq w \leq p\right\}
$$

with $\pi(p, w)$ defined by equation (9). 
In the case of identical firms, with $\lambda_{1}>0$, Mortensen (1990) and Burdett and Mortensen (1998) show that there is a unique continuous distribution $F_{0}$ as solution to problem (8), i.e.

$$
F_{0}(w)=\frac{1+\kappa_{1}}{\kappa_{1}}\left[1-\sqrt{\frac{p-w}{p-\underline{w}}}\right]
$$

with $\underline{w}=\max \left\{\phi_{0}, w_{\min }\right\}<p$, where

$$
\phi_{0}=\frac{\left(1+\kappa_{1}\right)^{2} b+\left(\kappa_{0}-\kappa_{1}\right) \zeta p}{\left(1+\kappa_{1}\right)^{2}+\left(\kappa_{0}-\kappa_{1}\right) \zeta}
$$

with

$$
\zeta=\kappa_{1}-2 \beta+2 \frac{\beta(1+\beta)}{\kappa_{1}} \ln \left(1+\frac{\kappa_{1}}{1+\beta}\right),
$$

is the unemployed workers' reservation wage when the legal minimum wage is not binding. Otherwise, the smallest wage offer is equal to legal minimum wage. In any case, the unemployed accept any wage offer. This equilibrium is in mixed strategy form (or asymmetric in pure strategies) because identical firms offer different wages. ${ }^{4}$

Finally, note that, since wage offers do not exceed productivity values, $E_{F}(w) \leq$ $E_{\Gamma}(p) \leq E_{\Gamma_{0}}(p) / \bar{\Gamma}_{0}(\underline{p})<\infty$, and, as a result, $\phi$ is finite.

Analogously to Mortensen (1990), a list of properties of any equilibrium wage offer distribution $F$ can be derived (see BRVdB for technical details). First of all, if employed workers receive alternative offers $\left(\kappa_{1}>0\right)$, then a wage offer $w$ that attracts workers is profit maximizing for employers of type $p>w$ only if no mass of other employers offer $w$. Consequently, the equilibrium wage offer distribution has no mass point. This is a fundamental property of equilibrium search models with on-the-job search. It is a consequence of the fact that a mass point at say $w^{*}$ induces firms paying $w^{*}$ to offer a wage slightly higher than $w^{*}$, because then its steady-state labor force will be substantially larger at the cost of only a second order decrease in the profit per worker.

Secondly, it can be shown that in any equilibrium, the set $K_{p}$ of profit maximizing wages of type- $p$ firms is closed and connected, for any $p$, and that the support of the distribution $F(\cdot)$ is connected.

\section{Equilibrium when the Distribution of Firms' Types is Continuous}

\subsection{The Equilibrium Solution}

In this section, we examine in detail the equilibrium solution in case the distribution $\Gamma(p)$ is continuous. We start by deriving expressions for the equilibrium solutions in

\footnotetext{
${ }^{4}$ In fact, Mortensen gives this solution for $\phi$ only for the case $\beta=0$ (i.e., zero discounting). It is however rather straightforward to generalize his formula. Also note that in the general case it remains true that when $\kappa_{1}$ tends to 0 , then $\zeta$ is equivalent to $\kappa_{1}$, and $\phi_{0}$ tends to $b$.
} 
terms of the primitives of the model. Then we prove a number of properties for the equilibrium, and we examine empirically informative implications of the theoretical model. Before that, we proceed to derive the cornerstone proposition of the theory: with a continuum of firms' types, firms' equilibrium strategies are pure strategies.

Proposition 3 If the distribution $\Gamma$ of labor productivities is continuous, then there exists a function $K$ mapping $\operatorname{supp}(\Gamma)$ into $\operatorname{supp}(F)$, such that $K_{p}=\{K(p)\} \Gamma$-almost surely.

See the Appendix for the proof. It thus follows that, when there is a continuous distribution of firms' types, the only equilibrium strategies are pure strategies. At the equilibrium, only one wage can be profit maximizing for a firm of a given type. The distribution of wage offers is $F(w)=\Gamma\left(K^{-1}(w)\right)$ where $K$ is an increasing, continuous function on $[\underline{p}, \bar{p}]$. Note that $K^{\prime}(p)$ need not exist everywhere, since the density $\gamma(p)$ associated with $\Gamma(p)$ need not be continuous. If $\gamma(p)$ is not continuous then $K^{\prime}$ is to be interpreted as the left-derivative of $K$. For convenience, we will assume in the sequel that the density $\gamma(p)$ is continuous and positive on the support of $\Gamma$.

From Section 2 it follows amongst other things $(i)$ that a higher productivity $p$ is associated with a higher offered wage $K(p)$, for all $p$, with $K(p)$ continuous, $(i i)$ that the distribution $F(w)$ is continuous and that it has a connected support, and (iii) that $\underline{w}=\max \left\{\phi, w_{\min }\right\}$.

Now consider the steady state profit flow $\pi(p, w)$ of a firm with productivity $p$ offering $w$ : there holds that $\pi(p, w)=(p-w) l(w)$, with $l(w)$ as specified earlier. The optimal $w=K(p)$ given $p$ and $F$ follows from first order conditions: by taking $\partial \pi(p, w) / \partial w=0$ we obtain:

$$
-\left[1+\kappa_{1} \bar{F}(w)\right]+2 \kappa_{1} f(w)(p-w)=0,
$$

under the restriction that $w \geq \max \left\{\phi, w_{\text {min }}\right\}$, where $w=K(p)$ and $f(w)$ is the density associated with $F(w)$. Firms with the lowest possible $p$ (i.e. with $\underline{p}$ ) offer a wage equal to $\underline{w}$, which equals $\max \left\{\phi, w_{\min }\right\}$. Equation (12) is an implicit equation for $w$ given $p$ and $F$. For $p$ in the interior of $\Gamma$, the solution is in the interior of $F$. Although we do not use equation (12) in the upcoming derivation of the expressions, it turns out to be useful for other purposes later on. At this stage we proceed as if the second order conditions (which can be stated as a condition in terms of $F$ and $f$ ) are satisfied. Below we then verify that this condition is met by the equilibrium solution.

The profit flow $\pi(p)$ of a firm with productivity $p$ offering $K(p)$ is $(p-K(p)) l(K(p))$. Differentiation with respect to $p$, using the Envelope Theorem, gives that $\pi^{\prime}(p)=$ $l(K(p))$. This remarkably simple result can be understood as follows. A marginal increase of $p$ has four immediate implications on $\pi(p, w)$ : (1) each worker makes more products, (2) there are additional workers who also produce products, (3) for each worker the wage increases, and (4) the additional workers have to be paid as well. Now, for any given $p$, the optimal wage is always such that a marginal increase in the wage bill (i.e. the payment of (3) and (4)) is exactly covered by the corresponding 
marginal increase in the revenue (i.e. by (2)). This follows directly from the first order condition for $w$ and is a well-known result in monopsony theory; see e.g. Card and Krueger (1995). As a result, the net increase in profits $\pi^{\prime}(p)$ is equal to (1), i.e. to the sum of the additional products made by each member of the original workforce (which in turn simply equals the size of the original workforce $l(K(p))$ ). Note that $\pi^{\prime}(p)=l(K(p))$, together with the facts that $l$ and $K$ are increasing, imply that the profit flow $\pi(p)$ is convex in $p$. This suggests that high-productivity firms have much more monopsony power in the labor market than low-productivity firms. We return to this later on.

The boundary condition associated with the differential equation $\pi^{\prime}(p)=l(K(p))$ follows from $\pi(\underline{p})=(\underline{p}-\underline{w}) l(\underline{w})$. Thus,

$$
\pi(p)=(\underline{p}-\underline{w}) l(\underline{w})+\int_{\underline{p}}^{p} l(K(x)) d x .
$$

Since, moreover, $\bar{F}(K(x))=\bar{\Gamma}(x)$, then

$$
l(K(x))=\frac{A}{\left[1+\kappa_{1} \bar{\Gamma}(x)\right]^{2}} .
$$

As a result,

$$
\begin{aligned}
\pi(p) & =A\left[\frac{\underline{p}-\underline{w}}{\left[1+\kappa_{1}\right]^{2}}+\int_{\underline{p}}^{p} \frac{d x}{\left[1+\kappa_{1} \bar{\Gamma}(x)\right]^{2}}\right] \\
& =A \int_{\underline{w}}^{p} \frac{d x}{\left[1+\kappa_{1} \bar{\Gamma}(x)\right]^{2}}
\end{aligned}
$$

Equation (13) expresses $\pi(p)$ in terms of $p, \Gamma, \phi, w_{\text {min }}, \kappa_{0}, m$ and $\kappa_{1}$. Apart from $\phi$, these are true primitives of the model. Note that $\lim _{p \rightarrow \underline{p}} \pi^{\prime}(p)=A /\left(1+\kappa_{1}\right)^{2}<A=$ $\lim _{p \rightarrow \bar{p}} \pi^{\prime}(p)$.

From $\pi(p)=(p-K(p)) l(K(p))$ it follows that $K(p)=p-\pi(p) / l(K(p))$. Substitution of $\pi(p)$ and $l(K(p))$ gives $w=K(p)$ in terms of $p, \Gamma, \phi, w_{\min }$ and $\kappa_{1}$. For this to be the optimal wage policy of a type $p$ firm, we need to verify the second order conditions of the firms' maximization problem. It is not difficult to show that the $K(p)$ above satisfies

$$
K^{\prime}(p)=\frac{2 \kappa_{1} \gamma(p)}{1+\kappa_{1} \bar{\Gamma}(p)}(p-K(p))
$$

This can be rewritten as the first-order condition. The condition that $K^{\prime}(p)>0$ is then equivalent to the second-order conditions (see also the proof of Proposition 6 below). Thus,

Proposition 4 The wage offer $w \equiv K(p)$ of a firm with productivity $p$ equals

$$
K(p)=p-\left[1+\kappa_{1} \bar{\Gamma}(p)\right]^{2} \int_{\underline{w}}^{p} \frac{d x}{\left[1+\kappa_{1} \bar{\Gamma}(x)\right]^{2}} .
$$


This equation is the central equation of the model.

Now that we have characterized the optimal strategies of each worker and each firm conditional on the strategies of others, we can address the questions of the existence and multiplicity of market equilibrium. The Appendix contains a detailed analysis of these issues. Depending on the values of the structural determinants of the model, the set of equilibria is empty, contains one element, or contains more than one element. It is difficult to characterize under which conditions each of these occurs. The model is not recursive because the value of the reservation wage $\phi$ affects the minimum productivity $\underline{p}$ in the market. In the Appendix we show that if $\bar{p}$ is finite, then equilibrium exists, whereas in the opposite case there may be non-existence of equilibrium.

By substituting the reservation wage equation into (15) we obtain the expression for $K(p)$ given $p, \Gamma, b, \beta, \kappa_{0}$ and $\kappa_{1}$. By invoking $F(w)=\Gamma\left(K^{-1}(w)\right)$, we also obtain the expression for $F$ in terms of the primitives of the model. In general it is not possible to obtain closed-form expressions for $K(p)$ and $F(w)$. As a special case, if $\Gamma(p)$ is a uniform distribution or an exponential distribution then a closed-form expression for $K(p)$ can be derived. However, in the last case there is no closed-form solution for $K^{-1}(w)$, and therefore neither for $F(w)$.

\subsection{Elements of Comparative Statics}

We first consider the effect of a change of productivity on the wage. The derivative $d w / d p$ (or, equivalently, $K^{\prime}(p)$ ) cannot be bounded from above, since any value can be generated by choosing an appropriately large value of $\gamma(p)$. By implication, the monopsony power index $(p-w) / p$ need not be a monotone function of $p$. In particular, $d w / d p$ can exceed one $e^{5}$. If $\bar{p}=\infty$ then, however, it is not possible to have $d w / d p$ uniformly bounded away from one, because $w \leq p$. We will see below that if $\bar{p}=\infty$ then in general $d w / d p$ tends to zero and $(p-w) / p$ increases to one, for large $p$.

The derivation of comparative statics results for $K(p)$ is complicated by the effect that $\phi$ may have on $K(p)$. Let us for convenience assume that $w_{\min }>\phi$. By differentiation it follows that

Proposition 5 Let $w_{\text {min }}>\phi$. There holds that $d K(p) / d \kappa_{1}>0$ for all $p \in(\underline{p}, \bar{p})$.

This is intuitively plausible. If $\kappa_{1}$ is large then firms with high productivity have an incentive to offer a relatively high wage, since that will generate a huge inflow of workers. Stated differently, a large $\kappa_{1}$ reduces search frictions and therefore gives workers more market power and firms less (monopsony) power (note that the result above implies that the monopsony power index $(p-w) / w$ decreases in $\kappa_{1}$.) The condition above on $\phi$ could certainly be weakened; for $\kappa_{1}$ sufficiently close to $\kappa_{0}$, $\phi$ is close to $b$, and there should hold that $\phi<w_{\min }$.

\footnotetext{
${ }^{5}$ For example, if $\Gamma(p)$ is a uniform distribution on $[\underline{p}, \bar{p}]$ and $\underline{w}=\underline{p}$ then $d w / d p=2 \kappa_{1}(p-\underline{p}) /((1+$ $\left.\left.\kappa_{1}\right)(\bar{p}-\underline{p})\right)$ on the support of $\Gamma$.
} 
The fact that the wage offer increases in $\kappa_{1}$ does not imply that profits decrease in $\kappa_{1}$, because the increase of $\kappa_{1}$ also affects the steady state labor force of the firm. It is straightforward to show that an increase of $\kappa_{1}$ increases the labor force of high productivity firms (i.e. large firms) and decreases the labor force of low productivity firms (small firms). It can also be shown (from equation (13)) that an increase of $\kappa_{1}$ increases the profits of large firms and decreases the profits of small firms. To the extent in which the inequality of firm sizes and profits between firms is measured by differences between the largest and smallest firms, these results imply that the inequality of firm sizes and profits in the economy increases with an increase of $\kappa_{1}$. Note that for large firms an increase of $\kappa_{1}$ has the somewhat paradoxical result that the monopsony power decreases while the profits increase. This reflects the windfall profit of a reduction in search frictions.

As noted in Section 2, equilibrium in the homogeneous model is in mixed strategy form. This raises the question on how coordination is achieved: what determines the ranking of firms on the wage scale if they have an identical production technology? It can be shown that the equilibrium solution in the homogeneous model can be regarded as the limiting case of the solution in models in which $p$ is dispersed, when the degree of dispersion in $p$ goes to zero. In particular, both the wage offer distribution and the reservation wage converge to the corresponding solution in the homogeneous model (see BRVdB for a proof).

This is a remarkable result, and it has a number of implications. First of all, the mixed strategy equilibrium in the homogeneous model can be justified as a limit of a sequence of pure strategy equilibria in a game in which the firms' productivities (or the firms' perceptions of other firms' productivities) are appropriately disturbed. In other words, coordination between firms in the homogeneous model can be achieved by letting perceived differences between production technologies of firms go to zero. This result is an example of the general game-theoretic principle of purification of mixed strategy equilibria (see Fudenberg and Tirole (1992) for a survey and Hendricks and Porter (1988) for an application in auction theory).

The second implication concerns the nature of wage dispersion. Recall that if there is no search on the job then there is no wage dispersion, whether firms are heterogeneous or not. So $\lambda_{1}>0$ is necessary and sufficient for wage dispersion, and $\operatorname{Var}(p)>0$ is neither necessary nor sufficient for wage dispersion. However, the shape of $\Gamma$ affects the shape of $F$, and at first sight it may seem that the shapes of the equilibrium wage offer distribution $F$ in heterogeneous models are fundamentally different from the shape in the homogeneous model. The result above refutes this view. It implies that the shape of $F$ in the general model can be meaningfully decomposed into two components: a component that is present even if there is no heterogeneity, and a remainder component which is only present in case of heterogeneity of production technology. If there is almost no productivity heterogeneity then $F$ is almost the same as in the homogeneous model, so the shape of $F$ is mostly determined by the trade-off between profit per worker and number of workers, rather than by the fact that firms have different production 
technologies. In that case, the second component is "small" (note that these notions are vague in that we have not specified the appropriate measures).

The third implication concerns an empirical issue. We have derived that if there is not much variation in $p$ then $F(w)$ resembles the wage offer distribution in the homogeneous model. The wage offer distribution for the homogeneous model has a notoriously bad fit. Thus, a model in which there is not much variation in $p$ will not fit the wage offer data well.

\subsection{Admissible Equilibrium Wage Distributions}

In this subsection we characterize the set of admissible equilibrium wage (offer) distributions, i.e. the set of $F$ and $G$ that can be generated with the model. After that we derive properties of the tails of $F$ and $G$ and we mention some empirical implications.

\section{Admissible shapes}

Proposition 6 Given $\kappa_{1}$, the set of admissible $F$ (with lower bound of support $\underline{w}$ ) that can be generated by the model is characterized by the following two conditions: (i) $\underline{w} \geq w_{\text {min }}$, and (ii) $f(w)\left(1+\kappa_{1} \bar{F}(w)\right)$ decreases on its support. For $G$, (ii) has to be replaced by (ii)' $g(w)\left(1+\kappa_{1} G(w)\right)^{-3}$ decreases on its support.

The proof is in the Appendix to this paper.

In the homogeneous model there holds that $f(w)\left(1+\kappa_{1} \bar{F}(w)\right)$ is constant. So, somewhat loosely, one may say that $f(w)$ is not allowed to increase as fast as in the homogeneous model. This can be regarded as an advantage from an empirical point of view. Sufficient for $f(w)\left(1+\kappa_{1} \bar{F}(w)\right)$ to decrease is that $F$ has a decreasing density $f(w)$. For moderate and large values of $\kappa_{1}$, the condition in Proposition 6 is very weak in the sense that it is satisfied even if $f$ increases quite steeply. For small $\kappa_{1}$ the condition is violated even if $f$ increases only moderately.

The result in Proposition 6 implies that economic theory imposes testable restrictions on the distribution of observables. In particular, our theory excludes certain shapes for $F(w)$ and $G(w)$. As a result, the theory can be tested.

\section{Tail properties}

We already know that the lower bound of the support of $F$ and $G$ is $\underline{w}=\max \left\{\phi, w_{\min }\right\}$. Now let us examine the values of the corresponding densities $f$ and $g$ at $\underline{w}^{+}$. From equation (12), there holds that $f(w)=\left(1+\kappa_{1} \bar{F}(w)\right) /\left(2 \kappa_{1}(p-w)\right)$. Thus,

$$
\lim _{w\rfloor \underline{w}} f(w)=\frac{1+\kappa_{1}}{2 \kappa_{1}(\underline{p}-\underline{w})} .
$$

As a result,

Proposition 7 The densities $f$ and $g$ have an infinitely high peak at the lowest wage if and only if this wage is equal to the lower bound of the support of the productivity distribution. Specifically, 
- $f\left(\underline{w}^{+}\right) \in(0, \infty)$ iff $g\left(\underline{w}^{+}\right) \in(0, \infty)$ iff $\underline{p}=\underline{p}_{0}>\max \left\{\phi, w_{\min }\right\}(=\underline{w})$,

- $f\left(\underline{w}^{+}\right)=\infty$ iff $g\left(\underline{w}^{+}\right)=\infty$ iff $\underline{p}=\max \left\{\phi, w_{\text {min }}\right\}(=\underline{w})$.

The results for $g$ follow from application of the equilibrium flow condition relating $F$ and $G$.

The intuition behind this result is that low productivity firms have to pay more than the wage floor $\underline{w}$, while they obviously also pay less than their productivity level. This creates a congestion at the lowest wages in the wage distributions.

The result above implies that, in conventional parametric Maximum Likelihood Estimation, any a priori choice of (the support of) the productivity distribution has immediate consequences for the fit to the left tail of the wage densities. This may be unsatisfactory from an empirical point of view, especially in light of the recent strong interest in the appearance of a spike of the wage density at the minimum wage (see Card and Krueger (1995)). One way to get around this is to choose a family of distributions for $\Gamma$ for which the lower bound of the support $\underline{p}$ is an unknown parameter. Note that $\underline{p}>\underline{w}$ can be justified by fixed costs of production or entry costs.

We now turn to the behavior of $F$ and $G$ at the upper bound of their support. It can be established that the upper bound $\bar{w}$ is finite and equal to

$$
\bar{w}=\underline{w}+\int_{\underline{w}}^{\bar{p}}\left(1-\frac{1}{\left[1+\kappa_{1} \bar{\Gamma}(x)\right]^{2}}\right) d x<\infty
$$

(see BRVdB). Therefore, families of wage (offer) distributions with support extending to $\infty$ are not supported by the model. The upper bound of the wage offer distribution can be bounded as follows:

$$
\underline{p}-\frac{\underline{p}-\underline{w}}{\left(1+\kappa_{1}\right)^{2}} \leq \bar{w} \leq \underline{p}-\frac{\underline{p}-\underline{w}}{\left(1+\kappa_{1}\right)^{2}}+2 \kappa_{1}\left(E_{\Gamma}(p)-\underline{p}\right) .
$$

The finiteness of $\bar{w}$ implies that firms with a high productivity have very high monopsony power. Indeed, if $\bar{p}=\infty$ then the monopsony power index $(p-w) / p$ tends to its maximum value 1 for high values of $p$. This is in sharp contrast to the position of low productivity firms. If $\underline{p}=\underline{w}$ then the firms with the lowest productivity have a monopsony power index of 0 . The latter is obviously due to the fact that firms must pay more than the wage floor. For firms at the lower end of the market, the mandatory minimum wage and the unemployment benefits scheme destroy monopsony power almost completely. Hence, although on-the-job search induces wage dispersion, the additional competition between firms induced by on-the-job search is not sufficient to imply substantial rent sharing when firms' productivities can take on very high values. The firms at the upper end of the market do not have to fear much competition, as most other firms have lower productivity and lower wages.

The derivation of comparative statics results for $\bar{w}$ is complicated by the effect that $\phi$ may have on $\bar{w}$. Let us for convenience assume that $w_{\text {min }}>\phi$. Then an increase in 
$\kappa_{1}$ has a positive effect on $\bar{w}$ (note that for sufficiently large $\kappa_{1}$ there always holds that $\left.\phi<w_{\text {min }}\right)$. This is intuitively plausible. If $\kappa_{1}$ is large then firms with high productivity have an incentive to offer a relatively high wage, since that will generate a huge inflow of workers. Stated differently, a large $\kappa_{1}$ reduces search frictions and therefore gives workers more market power and firms less (monopsony) market power. Also, if $\Gamma$ is replaced by a distribution that is first-order stochastically dominating, or if $\underline{p}$ increases, then $\bar{w}$ increases. Again, these results are intuitively plausible. If $\Gamma$ is shifted towards the right then there are more competing high-productivity firms, inducing higher wages.

Let us now consider $f$ and $g$ at $\bar{w}$. From $f(w)=\left(1+\kappa_{1} \bar{F}(w)\right) /\left(2 \kappa_{1}(p-w)\right)$ it immediately follows that

$$
\begin{aligned}
& \lim _{w \uparrow \bar{w}} f(w)=0 \text { iff } \lim _{w \uparrow \bar{w}} g(w)=0 \text { iff } \bar{p}=\infty \text {, and } \\
& \lim _{w \uparrow \bar{w}} f(w) \in(0, \infty) \text { iff } \lim _{w \uparrow \bar{w}} g(w) \in(0, \infty) \text { iff } \bar{p}<\infty
\end{aligned}
$$

The proposition below characterizes the shape of the right-hand tails of $f(w)$ and $g(w)$ in terms of the shape of the right-hand tail of $\gamma(p)$.

Proposition 8 Let the density $\gamma(p)$ be monotone for all sufficiently large $p<\bar{p}$. The densities $f(w)$ and $g(w)$ of any equilibrium have a flat right tail (i.e. $\lim _{w \uparrow \bar{w}} f^{\prime}(w)=0$ and $\lim _{w \uparrow \bar{w}} g^{\prime}(w)=0$ ) if and only if the right-hand tail of $\gamma(p)$ goes to zero at a rate slower than $p^{-3}$ (i.e. if and only if $\lim _{p \nmid \bar{p}} p^{3} \gamma(p)=\infty$ ). If the right-hand tail of $\gamma(p)$ goes to zero at a rate faster than $p^{-3}$ then $\lim _{w \uparrow \bar{w}} f^{\prime}(w)=\lim _{w \uparrow \bar{w}} g^{\prime}(w)=-\infty$. If it goes to zero at the rate $p^{-3}$ then both $f^{\prime}(w)$ and $g^{\prime}(w)$ converge to a finite negative number.

The proof is in the Appendix to this paper.

The model has thus definite predictions about the right-hand tail of the productivity distribution. For almost all popular families of continuous distributions with support ranging to infinity there holds that the right-hand tail of the density goes to zero faster than $p^{-3}$ (e.g., this holds for Normal, Lognormal, Exponential, Logistic, Gamma and Weibull families). Suppose that $\Gamma_{0}$ belongs to one of these families. In that case, $\Gamma$ equals $\Gamma_{0}$ truncated from below at $\underline{w}$. The corresponding densities $f(w)$ and $g(w)$ then typically have a mosque-shaped form (i.e. a high peak at the left due to $\underline{p}=\underline{w}$, and a dome-shaped form to the right of it, crossing the horizontal axis vertically at $\bar{w}$ due to the proposition above). Obviously, this does not give a good fit to wage data. In particular, wage data typically display a flat right-hand tail, implying that the righthand tail of $\gamma(p)$ goes to zero at a rate slower than $p^{-3}$. This illustrates that it may be hazardous to estimate the model by parametric maximum likelihood, relying on a parametric functional form for $\Gamma(p)$, since such a procedure may give a bad fit to the right-hand tail of the wage data. Given the strong empirical evidence that the crosssectional wage density slowly goes to zero when wage become large, we expect a very fat right-hand tail for the productivity distribution. 
The Pareto family of distributions $\left(\Gamma(p)=1-(\underline{p} / p)^{\nu}, p \in(\underline{p}, \infty)\right.$ and $\underline{p} \geq$ $\left.\max \left\{\phi, w_{\min }\right\}\right)$ does allow for a right-hand density tail that goes to zero slower than $p^{-3}$. This family has the additional advantage that the lower bound of the support is an unknown parameter, which ensures that the shape of the wage offer density at the minimum wage is not fixed in advance. However, in practice this family for $\Gamma$ does not give quite a sufficiently accurate fit to the wage data densities either (see below).

\section{Empirical Application}

In this section we structurally estimate the model, using longitudinal survey data on labor supply behavior over time. We start with a discussion of these data. Then we develop a structural nonparametric estimation method for the productivity distribution. After that we consider firm data in order to obtain a confirmation, or a rejection, of the model predictions on the relation between firms' wages and productivities. We also compare the firm data to the estimates based on the labor supply data.

\subsection{The Labor Force Survey}

For the estimation of the model we use data from the French Labor Force Survey collected by the INSEE. In its present form, this panel survey started in 1991. In March every year, the sample is partially renewed each year (a third is dropped) so that an individual is interviewed in three consecutive years. We use the data of those who entered the survey in 1991.

An effort is made to collect extensive information on the labor market behavior of the individual respondents in the year preceding the moment of the interview. From this we obtain a sequence of labor market states occupied by the individuals and the sojourn times (spells) in these states. In particular, we have such trajectories from March 1990 to March 1993. A number of individual characteristics is recorded at the first interview of the respondent.

The first spell we use is the spell which is in progress at the date of the first interview. For computational reasons, information on subsequent spells is not used. Individuals who were self-employed for some period during the time span covered by the survey are dropped, since it is likely that the behavior of such individuals, at least in a certain period, deviates substantially from the behavior as described by the model. For similar reasons, we do not use information on respondents who are observed to be nonparticipant in the labor market for some period. An alternative approach would be to extend the model to include a state of nonparticipation, and allow for transitions to and from this state. Van den Berg and Ridder (1993) develop such a model. It turns out that the main features of the model are insensitive to the inclusion of such a state. Moreover, transitions to and from nonparticipation are rare in the data. Therefore, using information on such transitions in an extended model would, except for a number of imprecisely estimated nuisance parameters, probably not result in any gains. 
We stratify the data by industry, using the first digit of the industry code. In this procedure, we exclude individuals associated to the agricultural, energy, housing, insurance and public sector of the economy, because the number of observations in these sectors is too small, and/or because it can be argued that firms in these sectors are not profit maximizing. We estimate our model separately for each of the remaining 8 industries. This means that we assume homogeneity amongst workers within a single industry. It could be argued that there is substantial heterogeneity of individual-specific productivity of workers within a given industry. This criticism is also valid for stratifications based on other observables (like level of education or occupation). The reasons for choosing industry as stratifying variable are, firstly, that workers more often stay within the same industry than within the same occupation, and, secondly, that the firm data we use later on can only be stratified according to industry (and not according to occupation). We also report results for the whole sample, which includes those industries that we do not study separately.

The mandatory minimum wage $w_{\min }$ is known from institutional sources (it equals 4497 French Francs per month). ${ }^{6}$ The raw data contain some full-time wages below $w_{\text {min }}$. This may be due to reporting errors ${ }^{7}$ or to individuals having jobs as part of a schooling program. To deal with this, we replace all full-time wages below $w_{\min }$ by missing values. We also trim the high-wage data by discarding the $1 \%$ largest wages of the sample per industry.

The final sample selection is as follows. From the 45224 respondents in 1991 we dropped individuals who at some stage were student (5793 observations), in military service (401 obs.), or another type of nonparticipant (like housewife; $24193 \mathrm{obs}$.). In addition, we dropped individuals who at the first interview were civil servant at the state administration (3803 obs.), farmer ( 877 obs.), self-employed (2235 obs.) or parttime worker (957 obs.). The selection reduces the number of labor market states to two: unemployment and full-time employment. Table 1 presents some sample statistics of the endogenous labor market variables.

Figure 5 plots kernel estimates of the density $g(w)$ of wages earned at the date of the first interview. (Here, the vertical lines indicate the 5 th, 25th, 50th, 75 th and 95th percentile of the distribution of the variable on the horizontal axis.) Clearly, they do not differ much across industries, although wage dispersion seems somewhat less in construction than in other industries.

We do not impose $b$ to equal the observed pecuniary unemployment insurance benefits. Because of the one-to-one relation between $b$ and $\phi$, the latter can therefore be regarded as a structural determinant. Thus, the structural model determinants that we will try to estimate are $\kappa_{0}, \kappa_{1}, \delta, \Gamma$ and $\phi$. Note that if $\phi<w_{\min }$ then $b$ and $\phi$ do not affect any observable behavior at all.

\footnotetext{
${ }^{6}$ The Labor Force Surveys records all monetary variables net of social security payments but not net of direct income taxes.

${ }^{7}$ For example, workers declare their monthly wage as well as the number of hours worked per week. If they declare working more hours than is acknowledged by their labor contract then the hourly wage may be lower than the mandatory minimum wage.
} 


\subsection{Likelihood Function and Estimation Method}

In its simplest form, the model has no observed explanatory variables, and the dependent variables are aspects of the individual labor market histories. To be specific, the dependent variables are:

- Position at the time of the first interview:

$$
\begin{aligned}
x & =1 \text { if unemployed }, \\
& =0 \text { if employed. }
\end{aligned}
$$

- Elapsed and residual duration in the position of the first interview:

$$
\begin{aligned}
t_{0 b} & =\text { elapsed unemployment duration } \\
t_{0 f} & =\text { residual unemployment duration } \\
d_{0 b} & =1 \text { if unemployment duration left-censored, otherwise }=0 \\
d_{0 f} & =1 \text { if unemployment duration right-censored, otherwise =0 } \\
t_{1 b} & =\text { elapsed employment duration } \\
t_{1 f} & =\text { residual employment duration } \\
d_{1 b} & =1 \text { if job duration left-censored, otherwise }=0 \\
d_{1 f} & =1 \text { if job duration right-censored, otherwise }=0
\end{aligned}
$$

- Paid and accepted wages:

$$
\begin{aligned}
& w_{0}=\text { wage accepted by unemployed individuals } \\
& w_{1}=\text { wage of employees at time of first interview }
\end{aligned}
$$

- First transition if employed at first interview:

$$
\begin{aligned}
v & =1 \text { if job-to-unemployment transition } \\
& =0 \text { if job-to-job transition }
\end{aligned}
$$

The model implies a particular distribution for all the dependent variables (see Van den Berg and Ridder (1998) and Koning, Ridder and Van den Berg (1995) for a more extensive exposition). We do not have complete information on all observations due to censoring or missing data. On the assumption that censoring is uninformative and that data are missing at random, one can easily modify the likelihood to deal with these complications. The likelihood of the sample is obtained by multiplication of the individual contributions. Let us derive the likelihood of an observation in the sample.

Let us first consider the case of a worker unemployed at the time of the first interview. The probability of drawing an unemployed worker is $u / m=1 /\left(1+\kappa_{0}\right)$. The distribution of both backward (elapsed) and forward (residual) unemployment durations is exponential. The exit rate from unemployment is $\lambda_{0}$ and the likelihood is thus:

$$
\frac{\lambda_{0}^{2-d_{0 b}-d_{0 f}}}{1+\kappa_{0}} \exp \left[-\lambda_{0}\left(t_{0 b}+t_{0 f}\right)\right] f\left(w_{0}\right)^{1-d_{0 f}} .
$$


Second, we derive the likelihood of an individual who is employed at the time of the first interview. The probability of sampling an employed individual is $1-u / m=$ $\kappa_{0} /\left(1+\kappa_{0}\right)$. The job duration given $w_{1}$ and the employment duration are exponentially distributed with parameters $\delta+\lambda_{1} \bar{F}\left(w_{1}\right)$ and $\delta$ respectively. The likelihood is thus

$$
\frac{\kappa_{0}}{1+\kappa_{0}} g(w)\left[\delta+\lambda_{1} \bar{F}\left(w_{1}\right)\right]^{1-d_{1 b}} \exp \left[-\left(\delta+\lambda_{1} \bar{F}\left(w_{1}\right)\right)\left(t_{1 b}+t_{1 f}\right)\right]\left[\delta^{v}\left(\lambda_{1} \bar{F}\left(w_{1}\right)\right)^{1-v}\right]^{1-d_{1 f}}
$$

In expressions (17) and (18), $f, g$ and $\bar{F}$ depend on the structural parameters of the theory. In particular, they are highly nonlinear functions of the productivity distribution $\Gamma$. Calculation of the likelihood contributions of the wage data is numerically cumbersome (most importantly, the inverse $K^{-1}$ of the function $K$ mapping from $p$ to $w$ has to be determined numerically, while the function $K$ itself contains an integral that has to be evaluated numerically). Moreover, as we have seen, for most well-known distributional specifications for $\Gamma$, the implied wage (offer) densities do not fit the corresponding data. Even for a Pareto distribution for $\Gamma$, the fit to the actual earnings density that we obtained is far from satisfactory (see BRVdB). We therefore develop a nonparametric estimation procedure.

Before considering any nonparametric estimation method, it is essential to address the question whether the model $\left(\Gamma, \lambda_{0}, \lambda_{1}, \delta, b\right)$ is nonparametrically identified from the data at hand (with nonparametrically we mean that $\Gamma$ is not restricted to a parametric family).

Proposition 9 Let $\rho$ be known. The model $\left(\Gamma, \lambda_{0}, \lambda_{1}, \delta, b\right)$ is identified from the worker data, with the qualification that $b$ is identified if and only if $\phi>w_{\text {min }}$.

From the likelihood function it is obvious that the frictional parameters are identified from the duration data. From the proof of Proposition 6 it immediately follows that, given $\kappa_{1}, \Gamma$ is identified from the empirical distribution of cross-sectional wages $G(w)$. The parameter $b$ is identified if and only if $\phi$ is identified (from $\underline{w}$ ), which occurs if and only if $\phi>w_{\min }$. Thus, observed wages and durations are sufficient to recover the firms' productivity distribution without a priori parametric assumptions. Moreover, recall from Proposition 6 that our theory excludes certain shapes for $F(w)$ and $G(w)$. As a result, our theory imposes testable restrictions on the distribution of observables. The procedure to prove nonparametric identification and the derivation of a testable implication from Theorem 6 are somewhat analogous to derivations in Guerre, Perrigne and Vuong (1995), which deals with structural estimation of first-price auction models.

Below we spell out the three steps of the nonparametric estimation procedure.

1. First, estimate $G$ and $g$ using a non parametric procedure (a kernel estimator for example; see below). Let $\widehat{G}$ and $\widehat{g}$ be such estimates. Conditional on $\kappa_{1}$, consistent estimates of $\bar{F}$ and $f$ are:

$$
\widehat{\bar{F}}(w)=\frac{1-\hat{G}(w)}{1+\kappa_{1} \hat{G}(w)}
$$


and

$$
\widehat{f}(w)=\frac{1+\kappa_{1}}{\left[1+\kappa_{1} \widehat{G}(w)\right]^{2}} \widehat{g}(w) .
$$

2. Secondly, replace $\bar{F}$ and $f$ in the likelihood function by the above expressions, and maximize the likelihood function with respect to $\kappa_{0}, \kappa_{1}$ and $\delta$.

3. Thirdly, estimate $p=K^{-1}(w)$ and $\gamma(p)$ using equations (A.7) and (A.9) derived in the Appendix:

$$
\begin{aligned}
p & =w+\frac{1+\kappa_{1} G(w)}{2 \kappa_{1} g(w)} \\
\gamma(p) & =\frac{2 \kappa_{1}\left[1+\kappa_{1}\right] g(w)^{3}}{3 \kappa_{1} g(w)^{2}\left[1+\kappa_{1} G(w)\right]^{2}-g^{\prime}(w)\left[1+\kappa_{1} G(w)\right]^{3}} .
\end{aligned}
$$

Notice that the estimates from the first two steps are only based on those parts of the model that describe worker behavior and the aggregate equilibrium worker flows. The part of the model that describes firm behavior does not enter the first or second step. The third step then exploits the latter part of the model (i.e., the first-order condition of firms) to estimate the productivity distribution. The estimates of the frictional parameters can thus be expected to be consistent under a wide range of models of firm behavior and wage determination, including different equilibrium search models, but also models in which workers simply receive a constant fraction of productivity. Basically, we exploit the fact that worker behavior given $F$ and $G$ is sufficient to identify the frictional parameters: workers merely focus on the ordering of their current (reservation) wage and the wage offer, and they are not concerned with the determinants of the underlying wage offer distribution.

Of course the third step is conditional on the model being well-specified, that is conditional on

$$
3 \kappa_{1} g(w)^{2}-g^{\prime}(w)\left[1+\kappa_{1} G(w)\right]>0
$$

for all $w$. In practice, in the second step, we first maximize the likelihood without this constraint. We then verify whether the admissibility condition is satisfied for all wages in the sample. If it is not then we constrain $\kappa_{1}$ in the second step to be such that

$$
\kappa_{1}=\max _{w} \frac{\widehat{g^{\prime}}(w)\left[1+\kappa_{1} \widehat{G}(w)\right]}{3(\widehat{g}(w))^{2}} .
$$

$\left(\widehat{G}(w)\right.$ and $\widehat{g}^{\prime}(w)$ may be obtained by integration and differentiation of $\left.\hat{g}(w)\right)$.

The nonparametric estimation method is computationally much simpler and faster than the ML estimation method. In particular, no numerical integration is needed, and 
no iterations are needed in the third step. In order to avoid a cumbersome derivation of asymptotics for our non-standard estimation method, we obtain consistent standard errors by bootstrapping the three-step estimation procedure (first step included).

The method for consistently estimating $\gamma(p)$ is somewhat analogous to a recently developed structural nonparametric estimation method for first-price auctions in the independent private-value paradigm (Guerre, Perrigne and Vuong (1995); see also Elyakime, Laffont, Loisel and Vuong (1994)). An essential complication in our case is the fact that the mapping from the observable (wage) to its determinant (productivity) depends on an unknown parameter $\left(\kappa_{1}\right)$, while in the auction model the mapping from the observable (bid) to its determinant (valuation) does not depend on unknown parameters.

We use a standard kernel estimator for $g(w)$. The estimates $\hat{G}(w)$ and $\hat{g}^{\prime}(w)$ are then obtained by integration and differentiation of $\hat{g}(w)$. From extensive simulations it follows that the choices of both the kernel and the bandwidth have negligible effects on the estimations of the frictional parameters (for a reasonable range of bandwidths). We therefore use gaussian kernels, and the bandwidth is chosen by rule of thumb. Note that we have to encounter the fact that the functions to estimate are defined on a compact set. The standard kernel density estimator: $\tilde{g}(w)=\frac{1}{n h} \sum_{i=1}^{n} K\left(\frac{w-w_{i}}{h}\right)$, where $w_{i}, i=1, \ldots, n$, are the observed wages, is asymptotically downward biased near the boundaries $\left(E \tilde{g}(w) \rightarrow \frac{g(w)}{2}\right)$. So, following Guerre, Perrigne and Vuong (1995) and exploiting the fact that the minimum and maximum statistics are super-consistent estimators, we corrected the standard kernel estimator in the following way:

$$
\widehat{g}(w)=\left[\frac{1}{n h} \sum_{i=1}^{n} \varphi\left(\frac{w-w_{i}}{h}\right)\right]\left[\int_{\frac{x-\widehat{w}}{h}}^{\frac{x-\widehat{\underline{w}}}{h}} \varphi(u) d u\right]^{-1}
$$

where $\Phi$ is the cdf of the standard normal distribution and $\varphi$ its density.

\subsection{Estimation Results Based on Labor Supply Data}

First of all, for each industry we observe wages at (or marginally above) the mandatory minimum wage $w_{\min }$ (see Subsection 4.1). We therefore conclude that $b$ and $\rho$ are such that $\phi<w_{\min }$, and we take $w_{m i n}=\underline{w}$.

Table 2 presents the estimation results on the frictional parameters, for all industries. The most striking result is that generally $\lambda_{0}$ is much larger than $\lambda_{1}$ (about ten times as large), even though $\lambda_{0}$ itself is quite small (the estimated average unemployment durations are between 12 and 16 months). In other studies, the estimates of these two parameters are usually close to each other; for example, Van den Berg and Ridder (1998) find that both $\lambda_{0}$ and $\lambda_{1}$ are generally close to 0.04 per month (our average estimated $\lambda_{0}$ and $\lambda_{1}$ are close to 0.07 and 0.008 per month). Kiefer and Neumann (1993) do find, like us, that $\lambda_{0}$ is generally about five times as large as $\lambda_{1}$; however, their estimates of $\lambda_{0}$ and $\lambda_{1}$ are almost twice as large as our estimates. Using direct 
information on numbers of job offers, Blau (1989) finds substantially higher values of $\lambda_{\mathbf{0}}$ and $\lambda_{1}$ in the US (see also Devine and Kiefer (1991)). In sum, the French labor market displays a very low level of search on the job, in comparison to other labor markets as well as in comparison to the amount of search by the unemployed in France. The facts that $\lambda_{1}$ is so much smaller than $\lambda_{0}$ and that $\phi<w_{\text {min }}$ imply that $b$ is very small.

The theoretical restriction on $\kappa_{1}$ is never violated. Thus, our theory is not rejected by the data (note that the results indicate that the labor markets do differ across industries, so that a merging of industries should lead to rejection). To put this differently, the model provides a perfect fit to the wage data. Figure 5 contains the estimates from the first step of the estimation procedure (see Subsection 4.1). ${ }^{8}$

Figure 6 plots the density $f(w)$ as implied from the estimated $g(w)$ and $\kappa_{1}$ from the first and second step, respectively. These graphs are in log-coordinates in order to examine to what extent the wage and wage offer distributions differ from a Pareto distribution (which has densities that are straight lines in log-coordinates) ${ }^{9}$. For each sector, the density $f(w)$ decreases on the whole support, and it displays a peak at $\underline{w}$. From Figure 5, $g(w)$ also decreases for most wages, although it sometimes increases for low wages. The latter is in line with the observation that cross-sectional wages are often approximately log-normally distributed. However, both $f(w)$ and $g(w)$ have right-hand tails that are not dissimilar from Pareto tails. It should also be noted, however, that a Pareto density has unbounded support, contrary to the wage and wage offer distributions.

We now turn to the shape of the estimated productivity density $\gamma(p)$ (see Table $3)$. Figure 7 plots the productivity density in log-coordinates for each industry. These densities are highly skewed to the right. They resemble Pareto densities for a wide range of values, although they are sometimes slightly convex on intervals, and, perhaps more importantly, they display a high peak at $\underline{p} .{ }^{10}$ In any case, the graphs in Figure 7 to the right of the first quartile display less curvature than those in in Figures 5 and 6. Regression of the log density on $\log$ productivity yields values between -2.79 and -3.09 , most being close to -3 which characterizes the thinnest tail for $\gamma(p)$ that is consistent with the model given that the wage density has a flat right tail (with the latter we mean that the density converges horizontally to zero; see Subsection 3.3). If we restrict attention to productivity values in excess of the third quartile then regression of the log density on $\log$ productivity yields a value between -2.32 and -2.70 , which is of course fully in accordance with the theoretical restrictions for equilibrium implementability. Figures 8 displays the quantile-quantile (QQ) plots of the wage distribution $(G)$ versus the distribution of productivities weighted by firm size $\left(G \circ K^{-1} ;\right.$ i.e. the productivities of the firms as distributed across the employed workers). The productivity distributions are much more dispersed and concentrated at extreme values than the wage distribu-

\footnotetext{
${ }^{8}$ In all the figures below, the vertical lines corresponds to the 5 th, 25th, 50th, 75 th and 95 th percentiles of the distribution of the $x$ variable.

${ }^{9}$ These would have to be parabolic in case of log-normal distributions.

${ }^{10}$ As noted in Subsection 4.2, imposition of a Pareto distribution for productivity does not give a good fit to the whole wage distribution.
} 
tions. The right-hand tails of the productivity densities are considerably fatter. The congestion of firms close to $\underline{p}$ causes the congestion of wage offers close to $\underline{w}$. Note that the fact that $\underline{p}$ exceeds $\underline{w}$ implies that there are positive fixed costs of production.

Figures 9 displays the estimated mapping from $\log w$ to $\log p$. The estimated wage offer function $K$ is a concave function of $p$, and it flattens out for sufficiently large $p$, in accordance to the percentile plots (Figure 8 ). For low productivity firms, the wage is strongly increasing as a function of productivity, whereas the wage is less sensitive to the productivity level for high-productivity firms. This is echoed in the results on the monopsony power index, which is defined as $(p-K(p)) / p$. The latter is of interest since it captures the degree in which firms exploit search frictions when they set their wages (and, in doing so, split the rents of the matches). Figure 10 plots monopsony power against $\log p$. It is clear that most of the increasing part of the curves is within the fourth quartile. Industries can be classified in two categories: those with monotonically increasing monopsony power (food, current consumption, trade and services), and those for which monopsony power is not monotone until productivity reaches approximately the median of its distribution, after which it monotonically increases (intermediary goods, equipment, construction, transport \& telecom). Recall that nothing prevents $K(p)$ to increase at a higher rate than $p$ itself, at small values of $p$. In general, in more than $50 \%$ of the firms, the wage constitutes well over $60 \%$ of the total productivity level (or revenue product). On the other hand, the $5 \%$ most productive firms have very high monopsony power, paying less than $25 \%$ of the productivity level. The firms in the transport \& telecom sector on average have relatively low monopsony power. This is caused by the exceptionally high job offer arrival rate for the employed in this sector (see Table 2).

The results thus indicate the presence of (high-productivity) firms with an enormous monopsony power, collecting huge profits. ${ }^{11}$ The rents of the matches between these firms and their workers can be redistributed by imposing a system of progressive profit taxes. Another way to redistribute the rents of matches is to increase $\kappa_{1}$, i.e. to stimulate on-the-job search and job-to-job transitions. This pushes the wage distribution in an upward direction. A comparison of the estimate of $\lambda_{1}$ to those from other countries suggests that there must be scope for such a policy in France. On-the-job search can be stimulated by subsidizing agencies that arrange contacts between workers and firms, or by making the costs of job search tax-deductible. Job-to-job transitions can be stimulated by subsidizing the costs of moving or by stimulating the use of insurance and pension schemes that are not restricted to single firms or sectors, so that workers do not have to give up certain rights and claims when they move from one firm or sector to another.

\footnotetext{
${ }^{11}$ Of course, it can be argued that firms with a large difference between $p$ and $w$ are simply firms with a large capital stock, which is not in our model. In the next subsection we return to this issue, since the firm data contain measures of firm capital.
} 


\subsection{What Do Firm Data Tell Us?}

The structural empirical analysis presented above produces striking predictions concerning the relation between wages and productivities across firms. Part of these may be due to the imposed theoretical structure. To investigate this, we perform a descriptive analysis of these relations in firm data containing direct information on productivities and wages.

In particular, we use INSEE's BIC ( Bénéfices Industriels et Commerciaux") data for 1992. The BIC is an annual administrative survey among French firms, collected for the national accounts of France. In these data, a firm is an enterprise rather than an establishment. Only firms employing more than 20 workers or with a cash flow above a given minimum value are in the sample. Small firms are therefore under-represented in the data. According to the theoretical model, the size of the firm is related to the productivity and wage of that firm, so we expect this sampling design to bias the estimation of the marginal (population) densities of $w$ and $p$ by the corresponding raw firm data densities. In particular, we expect the left-hand tails of the firm data densities to be thinner than the left-hand tails of the population densities. It is however plausible that estimates of measures of the relation between $w$ and $p$ are not affected by this sampling design, although, since there is no information on the smallest firms, we can expect the interval of $p$ on which we observe the relation between $w$ and $p$ to be a truncated version of the support of $\Gamma(p)$.

We use the first digit of the industry code to stratify the data, analogously to the individual data. Also, analogously to the latter data, we delete firms in the industries and sectors with a strong public service component (governmental services, financial services, insurance and energy), yielding 95,630 firm observations. We also restrict attention to firms declaring a positive value-added and trimmed the upper and lower percentile. We end up with 88,582 firm observations. The number of firm observations per industry varies from 3,784 (food) to 22,514 (services).

We use the total employer labor compensation cost ( frais de personnel"), divided by the annual average full-time employment, as our measure of the wage $w$ paid by the firm. In this subsection, we also use the terms "wage costs" and "mean wage costs" to denote this wage. Contrary to worker data, this wage includes social security costs, which in accounting terms are worker costs even though the money workers actually receive from firms is already amputed of social security costs (the latter on average equal about $20 \%$ of $w$ ). The firm's wage costs also include employer labor taxes (which on average equal about $40 \%$ of $w$ ). We use the value added inclusive of the costs of production factors ( "valeur ajoutée brute au coût des facteurs"), divided by the annual average full-time employment, as our measure of the productivity (or revenue product) $p$ of the firm. In this subsection, we use the terms "value-added" and "mean valueadded" interchangeably with productivity.

Abowd, Crépon, Kramarz, and Trognon (1995) and Abowd, Kramarz and Margolis (1998) discuss the BIC data in detail. Table 4 gives some summary statistics of the firm data (these include quantiles of the corresponding estimates of $F$ and $\Gamma$ ). The estimated 
quantiles of the productivity distribution are very different from those obtained with the worker data (see Table 3). Part of the discrepancy can be accounted for by omitted productivity components in the analysis of the previous subsection. For a start, the average wage costs and value-added in the firm data should be about $60 \%$ larger because of the labor taxes. ${ }^{12}$ Additional non-wage expenses for the firm that are proportional to the number of employees also have an increasing effect on the value-added. It thus seems that the order of magnitude of the predicted productivity distributions from the worker data is reasonably close to that estimated from the firm data. Trade and services are found to be the most dispersed industries, according to either dataset.

Using a similar sample from the BIC, Abowd, Kramarz and Margolis (1998) find that wages, productivity and profits are positively related across firms, which confirms our theory. We now go further by applying the nonparametric tools that have also been used for the individual data. Figures 11 and 12 plot kernel estimates of the data densities of $w$ and $p$, respectively, across firms. Like before, we use log coordinates to show to what extent the distributions resemble Pareto distributions. The most striking difference between these densities and the corresponding densities from the worker data concern the shapes in the first two quartiles. The worker data predict more firms with low wages and low productivity than the firm data, and the densities in the firm data show a hump shape very different from a Pareto density. A possible explanation of the differences at low $w$ and $p$ values may be the under-representation of small firms, but it seems unlikely that that would have such a large effect. Beyond the third quartile, the densities in the firm data seem well approximated by a straight line, like in the previous subsection. However, the slope is generally steeper than -3 , which implies that the prediction of Proposition 8 is violated, given that the wage density has a flat tail. In sum, it is reasonable to deduce that some main feature of the labor market is not captured by the model with firm heterogeneity only. ${ }^{13}$ Figure 13 displays QQ plots of $(p, w)$ combinations. The productivity distribution appears to be more concentrated at the limits of the support than the wage distribution (except for equipment and construction). This is also predicted by the worker data, but in that case the degree of concentration is much stronger.

Figure 14 displays the quartile regressions of $\log w$ on a 7th-order polynomial of $\log p$. The whole conditional distribution of wage costs is shifting to the right when productivity increases. Median wage costs are a concave function of the productivity, although not to the same degree as estimated from the worker data. The regressions

\footnotetext{
${ }^{12}$ Obviously, the relation between $w$ and $p$ is invariant to changes in the monetary unit. Let $w_{n e t}$ and $p_{n e t}$ denote the wage and productivity from the worker perspective (so $p_{n e t}$ is an artificial concept). If the firm wage cost equals $(1+\tau) w_{n e t}$ then the value-added (i.e., the productivity from the firm perspective) equals $(1+\tau) p_{n e t}$.

${ }^{13}$ Of course, in reality, a crude segmentation by industry does not give labor markets with fully homogeneous workers. If a segmentation by, say, occupation would give markets with homogeneous workers then the data by industry are statistical aggregates of such markets, which would complicate the interpretation and comparison of estimation results. Unfortunately, the firm data do not enable segmentation by occupation.
} 
clearly show that conditioning on productivity does not reduce the variance of wage costs to zero. This implies that some additional source of heterogeneity is at work in the firm data. The most obvious candidate is of course human capital heterogeneity. However, we have no theory to explain why workers' human capital heterogeneity would imply that the more productive firms have a larger between-firm variance of log wages.

Now let us turn to the monopsony power index $(p-w) / p$. In this subsection we will also refer to this as the "profit share", since it measures the share of the labor productivity that is not paid to the worker. Both terms are somewhat inappropriate because, as we will see below, other production factors are also paid out of this. Figure 15 plots the quartile regressions of the profit shares as functions of $\log p$. In worker data, predicted monopsony power may be increasing or decreasing for low $p$, and it is increasing and concave for high $p$. In firm data, it is always increasing. Note that the conditional variance can be quite large for low-productivity firms. This may well be partly due to measurement errors or short-term fluctuations. Most of these lowproductivity firms (especially those who pay high wages) have negative profit, and it is of course not possible to survive for a very long time with a negative steady-state profit.

The firm data confirm the result from Subsection 4.3 that the firms with the highest productivity have a very large monopsony power (although the order of magnitude of monopsony power as a function of $p$ is somewhat lower everywhere in the firm data). Of course, it can be argued that firms with a large difference between $p$ and $w$ are simply firms with a large capital stock, which is not in our model. Abowd, Kramarz and Margolis (1998) find that value-added per worker in French firms is an increasing function of the capital usage (as measured by total assets) per worker. However, their empirical relation between capital and value-added is not able to explain most of the difference between value-added per worker and the wage, for large firms. Figure 16 displays quantile regressions that relate productivity to gross capital equipment (at purchase cost) in our firm data. Clearly, this relation is positive, but it is not very strong. Two important insights follow from these quantile regressions. First, taking account of capital equipment is not sufficient to explain the distances between $p$ and $w$. This reinforces the conclusions on the presence of high-productivity firms with large monopsony power and high profits. Secondly, capital dispersion alone is not entirely responsible for productivity dispersion. Again, worker skill heterogeneity seems a likely candidate to fill these gaps.

Finally, we turn to the relation between productivity and the number of employees at the firm (the firm labor force). Kernel regressions on the firm data generally show a monotone positive relation, which confirms our theory. Figure 17, which provides quantile regressions on this, points out that such kernel (or ordinary) regressions can be somewhat misleading in this context. The quantile regressions clearly show how little the labor force is correlated with labor productivity. For services, the relation between firm size and productivity even seems to be negative. This suggests that the service sector is not adequately described by our model, for example because it consists 
of distinct subsectors with different fundamental parameters. Alternatively, the result for services may be due to the well-known difficulty with measuring productivity in the service sector.

\section{Conclusion}

In this paper we theoretically and empirically analyze a class of equilibrium search models of the labor market that incorporate features of (and generalizes) previously developed equilibrium search models. In particular, the models allow for on-the-job search as well as productivity dispersion across firms acting on a single labor market. Moreover, we allow for mandatory minimum wages. All of these have distinctive implications for the distribution of wages. Equilibrium may not exist and is not necessary unique. Under the assumption of the existence of an equilibrium, we derive properties and expressions for the optimal wage-setting policy of firms and the resulting endogenous equilibrium wage distributions, in terms of the primitives of the model. The wage as a function of the productivity is decreasing in the degree of search frictions on the market. This reflects the effect of these frictions on the power of both sides of the market. We characterize the set of wage offer and wage distributions that can be generated by the model, in terms of the value of the frictional parameter.

The paper contains an extensive structural empirical analysis of the equilibrium search model, using French longitudinal labor supply data. We pay particular attention to the fit of the model to the wage data. Maximum Likelihood estimation of models in which the productivity distribution is assumed to belong to parametric families does not give an acceptable fit to the wage data. To deal with this, we develop an estimation method that gives a nonparametric estimate of the productivity density, provided that the empirical wage density is consistent with the theory.

The estimation results show that the theory is not rejected by the data, so the model provides a perfect fit to the wage data. In contrast, the model without productivity dispersion cannot explain more than $10 \%$ of total wage variation in the data. So, although the mere possibility of on-the-job search is sufficient for wage dispersion, and productivity dispersion is neither necessary nor sufficient for wage dispersion, the inclusion of productivity dispersion is essential for a good fit. To put this differently, the interaction effect of on-the-job search and productivity dispersion is a more important determinant of wage dispersion than the marginal effect of on-the-job search.

The amount of on-the-job search on the French labor markets is rather small, in comparison to the amount of search by the unemployed as well as in comparison to other countries. As a result, high-productivity firms have substantial power to exploit search frictions, and, indeed, their wages are much smaller than their productivity level. To verify these results, we examine rather unique (French) firm data on productivities and wages. The firm data bear some resemblance to the estimation results based on worker data. Specifically, the wage and the profit share are increasing functions of labor productivity. This supports a theory of monopsonistic competition. 
The results suggest that the rents of matches between workers and firms with a very high productivity could be redistributed by imposing a system of progressive profit taxes. Another way to redistribute the rents of such matches is to stimulate on-the-job search and job-to-job transitions, e.g. by subsidizing the costs of moving. These economic policy considerations however must be taken very cautiously given that the theory does not account for different production factors and given that the theory does not explain the origins of productivity dispersion. Concerning the latter, it may be fruitful to extend the model along the lines of Acemoglu and Shimer (1997). In a rather different equilibrium search framework, they explain productivity dispersion out of capital dispersion, which in turn is supported as a mixed-strategy equilibrium for a priori equal firms. ${ }^{14}$

We spotted a number of differences between the firm data and the model as estimated from the worker data. Some of these can not be fully accounted for by firm-data imperfections (like the fact that small firms are excluded from the sample). Concerning the shape of the productivity density, the worker data suggest more probability mass at the highest and lowest productivity values than the firm data. There is also clear evidence of dispersion of offered wages, monopsony power and employment for a given productivity level. This suggests a need for incorporation of additional (worker) heterogeneity into the model. Dispersion of individual-specific productivity across workers is also essential in order to explain that workers earn different wages at the same firm (see Abowd, Kramarz and Margolis (1998) for evidence).

In general, these anomalies of the current model do not mean that the theory has to be abandoned. They just call for further empirical and theoretical research. For example, the richness of the firm data allows estimation of models with less simple production functions, with several labor production factors associated with different worker qualifications.

\section{Appendix. Proofs and Additional Theoretical Results}

Proof of Proposition 3 Let us first cover $\operatorname{supp}(\Gamma)$ by a countable union of bounded intervals: there exists a sequence $\left(p_{n}\right)_{n \in N}$ such that $\operatorname{supp}(\Gamma) \subseteq \bigcup_{n \in N}\left[p_{n}, p_{n+1}\right]$. For all $n$ and all integers $m>0$, let $\mathcal{P}_{m}^{n}$ be the subset of $\left[p_{n}, p_{n+1}\right]$ made of the values of $p$ for which $K_{p}$ is of Lebesgue measure greater than $\frac{1}{m}$. Since the sets $K_{p}$ do not intersect, $\operatorname{card}\left(\mathcal{P}_{m}^{n}\right) \leq m\left(p_{n+1}-p_{n}\right)<\infty$. Hence $\mathcal{P}_{m}^{n}$ is finite. Any value of $p$ for which $K_{p}$ is not a singleton, necessarily belongs to a union $\bigcup_{n>0} \mathcal{P}_{m}^{n}$ for some $m$. Then, the $\sigma$-additivity of probability measure $\Gamma$ and the fact that it is continuous, together imply that $\bigcup_{n, m} \mathcal{P}_{m}^{n}$ has $\Gamma$-probability zero.

\footnotetext{
${ }^{14}$ Note that our firm data seem to suggest that firm profits are not equal if one controls for capital, so that incorporating additional forms of heterogeneity may be important as well.
} 
Existence, Non-Existence, Uniqueness and Multiplicity of Equilibrium Let

$$
\begin{aligned}
L(x)= & \frac{\left(1+\kappa_{1}\right)^{2}}{\left(1+\kappa_{1}\right)^{2}+\left(\kappa_{0}-\kappa_{1}\right) \zeta}\left(b+\left(\kappa_{0}-\kappa_{1}\right) \int_{x}^{\bar{p}} s\left(\frac{\bar{\Gamma}_{0}(p)}{\bar{\Gamma}_{0}(x)}\right) d p\right)+ \\
& +\frac{\left(\kappa_{0}-\kappa_{1}\right) \zeta x}{\left(1+\kappa_{1}\right)^{2}+\left(\kappa_{0}-\kappa_{1}\right) \zeta}
\end{aligned}
$$

where

$$
s(t)=\frac{\kappa_{1} t^{2}-2 \beta t+2 \frac{\beta(1+\beta)}{\kappa_{1}} \ln \left(1+\frac{\kappa_{1} t}{1+\beta}\right)}{\left[1+\kappa_{1} t\right]^{2}} .
$$

The next proposition shows for which values of minimum productivity $\underline{p}$ a market equilibrium can be defined.

Proposition 10 (i) The set of all possible equilibria can be indexed by the infimum productivity $\underline{p}$ of active firms. The distribution of productivities of active firms is

$$
\Gamma(p)=\left[\Gamma_{0}(p)-\Gamma_{0}(\underline{p})\right] / \bar{\Gamma}_{0}(\underline{p}) ;
$$

the reservation wage is

$$
\phi=\frac{\left(1+\kappa_{1}\right)^{2}-\left(1+\beta+\kappa_{1}\right) \zeta}{\left(1+\kappa_{1}\right)^{2}\left(1+\beta+\kappa_{0}\right)}\left(\kappa_{0}-\kappa_{1}\right) \max \left(w_{\min }-L(\underline{p}), 0\right)+L(\underline{p}) ;
$$

the minimum wage offered is

$$
\underline{w}=\max \left(\phi, w_{\min }\right)
$$

the wage strategy of a type-p firm is a single wage $K(p)$ defined by equation (15).

(ii) Let $C$ denote the set of fixed points of $L$ which are greater than $\max \left(\underline{p}_{0}, w_{\text {min }}\right)$ :

$$
C=\left\{u \geq \max \left(\underline{p}_{0}, w_{\min }\right) \mid L(u)=u\right\}
$$

(C may be empty). The set of all minimum productivity values $\underline{p}$ defining a market equilibrium is:

$$
E= \begin{cases}\left\{\max \left(\underline{p}_{0}, w_{\text {min }}\right)\right\} \cup C & \text { if } L\left(\max \left(\underline{p}_{0}, w_{\text {min }}\right)\right) \leq \max \left(\underline{p}_{0}, w_{\text {min }}\right), \\ C & \text { otherwise. }\end{cases}
$$

Proof. Let us first derive the value $\phi^{*}$ of reservation wage when there is no legal minimum wage. Then $\underline{w}=K(\underline{p})=\phi^{*}$ and $\phi^{*}$ is necessarily such that:

$$
\begin{aligned}
\phi^{*} & =b+\left(\kappa_{0}-\kappa_{1}\right) \int_{\phi^{*}}^{\bar{w}} \frac{\bar{F}(w) d w}{1+\beta+\kappa_{1} \bar{F}(w)} \\
& =b+\left(\kappa_{0}-\kappa_{1}\right) \int_{\underline{p}}^{\bar{p}} \frac{\bar{\Gamma}(p)}{1+\beta+\kappa_{1} \bar{\Gamma}(p)} K^{\prime}(p) d p
\end{aligned}
$$


since, at the equilibrium, $\bar{F}(w)=\bar{\Gamma}(K(w))$. After integration by parts,

$$
\begin{aligned}
\phi^{*}= & \frac{\left(1+\kappa_{1}\right)^{2} b+\left(\kappa_{0}-\kappa_{1}\right) \zeta \underline{p}}{\left(1+\kappa_{1}\right)^{2}+\left(\kappa_{0}-\kappa_{1}\right) \zeta} \\
& +\frac{\left(1+\kappa_{1}\right)^{2}\left(\kappa_{0}-\kappa_{1}\right)}{\left(1+\kappa_{1}\right)^{2}+\left(\kappa_{0}-\kappa_{1}\right) \zeta} \int_{\underline{p}}^{\bar{p}} \frac{\kappa_{1} \bar{\Gamma}(p)^{2}-2 \beta \bar{\Gamma}(p)+2 \frac{\beta(1+\beta)}{\kappa_{1}} \ln \left(1+\frac{\kappa_{1} \bar{\Gamma}(p)}{1+\beta}\right)}{\left[1+\kappa_{1} \bar{\Gamma}(p)\right]^{2}} d p,
\end{aligned}
$$

where $\zeta=\kappa_{1}-2 \beta+2 \frac{\beta(1+\beta)}{\kappa_{1}} \ln \left(1+\frac{\kappa_{1}}{1+\beta}\right)$ and $\bar{\Gamma}(p)=\bar{\Gamma}_{0}(p) / \bar{\Gamma}_{0}(\underline{p})$.

Note that when $\kappa_{1}$ tends to 0 , then

$$
\kappa_{1} \bar{\Gamma}(p)^{2}-2 \beta \bar{\Gamma}(p)+2 \frac{\beta(1+\beta)}{\kappa_{1}} \ln \left(1+\frac{\kappa_{1} \bar{\Gamma}(p)}{1+\beta}\right) \sim \kappa_{1} \bar{\Gamma}(p)^{2}
$$

tends to 0 and therefore $\phi^{*}$ tends to $b$. If $\underline{p}=\bar{p}$, then $\phi^{*}=\phi_{0}$, the value obtained with no productivity dispersion.

We can rewrite the reservation wage as:

$$
\phi^{*}=L(\underline{p})
$$

where $L$ is defined by equation (A.1). We necessarily have that $L(\underline{p}) \leq \underline{p}$ (if not, $\underline{w}=\phi^{*}>\underline{p}$ and firms with productivity close to the infimum productivity would make negative profit). If $L\left(\underline{p}_{0}\right) \leq \underline{p}_{0}$, then $\underline{p}_{0}$ can be the infimum productivity of an equilibrium with reservation wage $\phi^{*}=L\left(\underline{p}_{0}\right)$, minimum wage offered $\underline{w}=\phi^{*}$ and $K(p)$ defined by eq (15). If $L(\underline{p})<\underline{p}$ and $\underline{p}>\underline{p}_{0}$, every firm with productivity between $\sup \left(\phi^{*}, \underline{p}_{0}\right)$ and $\underline{p}$ (where $\phi^{*}=L(\underline{p})$ ) can enter the market and make positive profit. Such a value of $\underline{p}$ thus cannot be an equilibrium in the sense of definition 1. Finally, any $\underline{p}>\underline{p}_{0}$, such that $L(\underline{p})=\underline{p}$, defines a valid value for the infimum productivity of an equilibrium. For such a value, we have $\underline{w}=\phi^{*}=\underline{p}$ ( firms with productivity below than $\underline{p}$ would make negative profit) and $K(p)$ is defined by equation (15).

If there is a legal minimum wage $w_{\text {min }}$ : either the constraint is not binding and the reservation wage is equal to $\phi^{*}=L(\underline{p})$, or it is binding. If so, we can derive the expression of the reservation wage $\widetilde{\phi}$, using equation (1) and the fact that $K(\underline{p})=$ $w_{\min }>\widetilde{\phi}^{15}$

$$
\tilde{\phi}=\frac{\left(1+\kappa_{1}\right)^{2} b-\left(1+\beta+\kappa_{1}\right) \zeta}{\left(1+\kappa_{1}\right)^{2}\left(1+\beta+\kappa_{0}\right)}\left(\kappa_{0}-\kappa_{1}\right)\left(w_{\text {min }}-L(\underline{p})\right)+L(\underline{p}) .
$$

It is obvious that any candidate for the infimum productivity at the equilibrium is greater or equal to $w_{\text {min }}$. Every equilibrium with infimum productivity $\underline{p}$ such that $\underline{p}>\underline{p}_{0}, L(\underline{p})=\underline{p}$ and $\underline{p} \geq w_{\min }$ is not affected by the introduction of a legal minimum wage. If $w_{\text {min }} \leq \underline{p}_{0}$ then $\underline{p}_{0}$ can be the infimum productivity of an equilibrium only if $L\left(\underline{p}_{0}\right) \leq \underline{p}_{0}$. Thus the reservation wage $\phi$ equals $\phi^{*}$ if $w_{\min } \leq \phi^{*}$ whereas it equals $\widetilde{\phi}$, if $w_{\text {min }}>\phi^{*}$. The minimum wage offer is then $\underline{w}=\max \left(w_{\text {min }}, \phi^{*}\right)$ and $K(p)$ is defined by equation (15). Finally, if $w_{\min }>\underline{p}_{0}$ then $\underline{p}=w_{\min }$ can be the infimum productivity of an equilibrium only if $L\left(w_{\min }\right) \leq w_{\min }$ (because otherwise the reservation wage would exceed the infimum productivity). This ends the proof.

The next corollary follows:

\footnotetext{
${ }^{15}$ One can easily prove that $L(\underline{p})<w_{\min } \Rightarrow \tilde{\phi}<w_{\min }$.
} 
Corollary 1 If $\bar{p}$ is finite then $E$ contains at least one point. If $\bar{p}=+\infty, E$ can be empty.

Proof. Let $q=\max \left(\underline{p}_{0}, w_{\min }\right)$. If $L(q) \leq q$ then $q \in E$. Else, if $\bar{p}$ is finite, we can easily prove that:

$$
L(x)_{x \rightarrow \bar{p}} \longrightarrow \frac{\left(1+\kappa_{1}\right)^{2} b+\left(\kappa_{0}-\kappa_{1}\right) \zeta \bar{p}}{\left(1+\kappa_{1}\right)^{2}+\left(\kappa_{0}-\kappa_{1}\right) \zeta}<\bar{p} \quad(\text { as } \bar{p}>b)
$$

and by the continuity of $L$, we know that it has a fixed point on $\left(\underline{p}_{0}, \bar{p}\right)$. Figures 1 and 2 present examples of such cases where there exists a unique equilibrium (the graph on top of each figure draws the productivity density, whereas the bottom graph draws the corresponding $L$ function and its position with the first bisecting line). Figure 3 provides an example with multiple equilibria.

If $\bar{p}$ is not finite, then the function $L$ does not necessary converge when its argument goes to infinity. We can thus observe all cases from no equilibrium to multiple equilibria. Figure 4 illustrates a situation where there is no equilibrium because $L$ has no fixed point on $] \underline{p}_{0},+\infty\left[\right.$ and $L\left(\underline{p}_{0}\right)>\underline{p}_{0}$.

Note that $\underline{p}=\underline{w}$ unless $\underline{p}=\underline{p}_{0}>\max \left\{L\left(\underline{p}_{0}\right), w_{\text {min }}\right\}=\underline{w}$, which corresponds to a situation in which any latent firms with a productivity between $\underline{w}$ and $\underline{p}$ have an incentive to enter the market. We shall later see that whether firms are thus constrained or not can be empirically verified since it will be shown that when firms are constrained, this has dramatic consequences on the form of the wage distribution at the minimum wage offer.

Proof of Proposition 6 First of all, any $\underline{w}>w_{\min }$ can be generated by choosing a value of $b$ such that $\underline{w}=\phi$, for any given $\kappa_{1}$.

In order to derive the set of admissible equilibrium wage distributions, it is convenient to derive $\Gamma$ in function of $F$. Then, an admissible $F$ will be one which yields a regular distribution $\Gamma$. Rewrite equation (12) as

$$
K^{-1}(w)=w+\frac{1+\kappa_{1} \bar{F}(w)}{2 \kappa_{1} f(w)} .
$$

Alternatively, since

$$
f(w)=\frac{\left[1+\kappa_{1}\right] g(w)}{\left[1+\kappa_{1} G(w)\right]^{2}}
$$

equation (A.5) can also be written as

$$
K^{-1}(w)=w+\frac{1+\kappa_{1} G(w)}{2 \kappa_{1} g(w)} .
$$

It is easily verified that conditions (ii) and $(i i)^{\prime}$ are equivalent to the requirement that $K^{-1}(w)$ in (A.5) and (A.7) is increasing in $w$. So the model implies that these conditions are satisfied. Also, if we start with an $F$ or $G$ satisfying these conditions then, using equations (A.5) and (A.7) as transformations from $w$ to $p$, we obtain a regular density $\gamma(p)$. 
Moreover:

$$
\begin{aligned}
\left(K^{-1}\right)^{\prime}(w) & =\frac{1}{K^{\prime}\left[K^{-1}(w)\right]} \\
& =\frac{\kappa_{1} f(w)^{2}-f^{\prime}(w)\left[1+\kappa_{1} \bar{F}(w)\right]}{2 \kappa_{1} f(w)^{2}} \\
& =\frac{3 \kappa_{1} g(w)^{2}-g^{\prime}(w)\left[1+\kappa_{1} G(w)\right]}{2 \kappa_{1} g(w)^{2}} .
\end{aligned}
$$

Substitution of $K^{\prime}\left[K^{-1}(w)\right]=\gamma(p) / f(w)$ gives

$$
\begin{aligned}
\gamma(p) & =\frac{2 \kappa_{1} f(w)^{3}}{\kappa_{1} f(w)^{2}-f^{\prime}(w)\left[1+\kappa_{1} \bar{F}(w)\right]} \\
& =\frac{2 \kappa_{1}\left[1+\kappa_{1}\right] g(w)^{3}}{3 \kappa_{1} g(w)^{2}\left[1+\kappa_{1} G(w)\right]^{2}-g^{\prime}(w)\left[1+\kappa_{1} G(w)\right]^{3}} .
\end{aligned}
$$

Obviously, the denominators of these expressions are positive for all $w$ if and only if conditions (ii) and ( $i)^{\prime}$ are satisfied (given suitable differentiability requirements). Equations (A.8) and (A.9) are useful below when we derive our nonparametric estimation method.

Taken as a model primitive, the density $\gamma(p)$ generates the same $f$ and $g$ as the ones from which it is constructed in (A.9) (intuitively, this is because both $K(p)$ in Section 3 and $K^{-1}(w)$ above essentially follow from the same first-order conditions (12)). So, given $\kappa_{1}$ and $\underline{w}$, there is a functional one-to-one relationship between $\gamma(\cdot)$ and $f(\cdot)$ or $g(\cdot)$.

Proof of Proposition 8 By differentiating equation (12) with respect to $w$ (keeping in mind that $p$ is related to $w$ by way of $w=K(p)$; note that the differentiation is allowed in the interior of $F$ ), we obtain

$$
f^{\prime}(w)=\frac{-f(w)}{2(p-w)}-\left(1+\kappa_{1} \bar{F}(w)\right) \frac{\left(\frac{d p}{d w}-1\right)}{2 \kappa_{1}(p-w)^{2}} .
$$

There holds that $d p / d w=f(w) / \gamma(p)$. By using equation (12) to substitute $f(w)$ from the latter, we obtain

$$
d p / d w=\frac{1+\kappa_{1} \bar{F}(w)}{2 \kappa_{1} \gamma(p)(p-w)}
$$

By substituting this into the above expression for $f^{\prime}(w)$ we obtain

$$
f^{\prime}(w)=\frac{-f(w)}{2(p-w)}-\frac{\left(1+\kappa_{1} \bar{F}(w)\right)^{2}}{4 \kappa_{1}^{2} \gamma(p)(p-w)^{3}}+\frac{\left(1+\kappa_{1} \bar{F}(w)\right)}{2 \kappa_{1}(p-w)^{2}}
$$

Now let $w \uparrow \bar{w}$ (so $p \uparrow \bar{p}$ ). Assume for the moment that $\bar{p}=\infty$. The first and third terms on the right-hand side both converge to zero, since $\bar{w}<\infty$ and $\lim _{w \uparrow} f(w)=0$. Thus, the limiting behavior of $f^{\prime}(w)$ is determined by the limiting behavior of the second term on the right hand side. The latter is determined by the limiting behavior of $p^{3} \gamma(p)$. For example, if $\gamma(p)$ goes to zero faster than $p^{-3}$ then $\lim _{w \uparrow \bar{w}} f^{\prime}(w)=-\infty$.

If $\bar{p}<\infty$ then $\gamma(p)$ goes to zero at the highest possible rate. It is straightforward to show that all these results on the limiting behavior of $f^{\prime}(w)$ are also valid for $g^{\prime}(w)$. 


\section{References}

Abowd, J.M., B. Crépon, F. Kramarz and A. Trognon (1995), "A la recherche des moments perdus: covariance models for unbalanced panels with endogenous death", Working paper, INSEE, Paris.

Abowd, J.M., F. Kramarz, and D.N. Margolis (1998), "High wage workers and high wage firms", Econometrica, forthcoming.

Acemoglu, D. and R. Shimer (1997), "Efficient wage dispersion", Working paper, Princeton University, Princeton.

Albrecht, J.W. and B. Axell (1984), "An equilibrium model of search unemployment", Journal of Political Economy, 92, 824-840.

Blau, D.M. (1989), "An empirical analysis of employed and unemployed job search behavior", Working paper, University of North Carolina, Chapel Hill.

Bontemps, C., J.M. Robin, and G.J. van den Berg (1997), "Equilibrium search with productivity dispersion: theory and estimation", Working paper, INSEE-CREST, Paris and Tinbergen Institute, Amsterdam.

Bowlus, A.J., N.M. Kiefer, and G.R. Neumann (1995), "Estimation of equilibrium wage distributions with heterogeneity", Journal of Applied Econometrics, 10, S119-S131.

Burdett, K. and D.T. Mortensen (1998), "Wage differentials, employer size, and unemployment", International Economic Review, forthcoming.

Card, D. and A.B. Krueger (1995), Myth and measurement, Princeton University Press, Princeton.

Devine, T.J. and N.M. Kiefer (1991), Empirical Labor Economics, Oxford University Press, Oxford.

Diamond, P.A. (1971), "A model of price adjustment", Journal of Economic Theory, 3, 156-168.

Eckstein, Z. and K.I. Wolpin (1990), "Estimating a market equilibrium search model from panel data on individuals", Econometrica, 58, 783-808.

Elyakime, B., J.J. Laffont, P. Loisel and Q. Vuong (1994), "First-price sealed-bid auctions with secret reservation prices ", Annales d'Économie et de Statistique, 34, 115-141.

Fudenberg, D. and J. Tirole (1992), Game Theory, MIT Press, Cambridge.

Guerre, E., I. Perrigne and Q. Vuong (1995), "Nonparametric estimation of first-price auctions", Working paper, INRA, Toulouse.

Hendricks, K. and R.H. Porter (1988), "An empirical study of an auction with asymmetric information", American Economic Review, 78, 865-883.

Kiefer, N.M. and G.R. Neumann (1993), "Wage dispersion with homogeneity: the empirical equilibrium search model", in H. Bunzel et al., editor, Panel data and labor market analysis, North Holland, Amsterdam. 
Koning, P., G. Ridder, and G.J. van den Berg (1995), "Structural and frictional unemployment in an equilibrium search model with heterogeneous agents", Journal of Applied Econometrics, 10, S133-S151.

MacMinn, R.D. (1980), "Job search and the labor dropout problem reconsidered", Quarterly Journal of Economics, 95, 69-87.

Mortensen, D.T. (1990), "Equilibrium wage distributions: a synthesis", in J. Hartog et al., editor, Panel data and labour market studies, North-Holland, Amsterdam.

Mortensen, D.T. and G.R. Neumann (1988), "Estimating structural models of unemployment and job duration in dynamic econometric modeling ", in Proceedings of the Third International Symposium in Economic Theory and Econometrics, Cambridge University Press, Cambridge.

Mortensen, D.T. and T. Vishwanath (1994), "Personal contacts and earnings: it is who you know!", Labour Economics, 1, 187-201.

Pissarides, C.A. (1990), Equilibrium Unemployment Theory, Basil Blackwell, Oxford.

Reinganum, J. (1979), "A simple model of equilibrium price dispersion", Journal of Political Economy, 87, 851-858.

Ridder, G. and G.J. van den Berg (1997), "Empirical equilibrium search models", in D.M. Kreps and K.F. Wallis, editors, Advances in Economics and Econometrics: Theory and Applications, Cambridge University Press, Cambridge.

Van den Berg, G.J. and G. Ridder (1993), "On the estimation of equilibrium search models from panel data", in J.C. van Ours et al., editor, Labor Demand and Equilibrium Wage Formation, North Holland, Amsterdam.

Van den Berg, G.J. and G. Ridder (1998), "An empirical equilibrium search model of the labor market", Econometrica, forthcoming.

Wernerfelt, B. (1988), "General equilibrium with real time search in labor and product markets", Journal of Political Economy, 96, 820-831. 


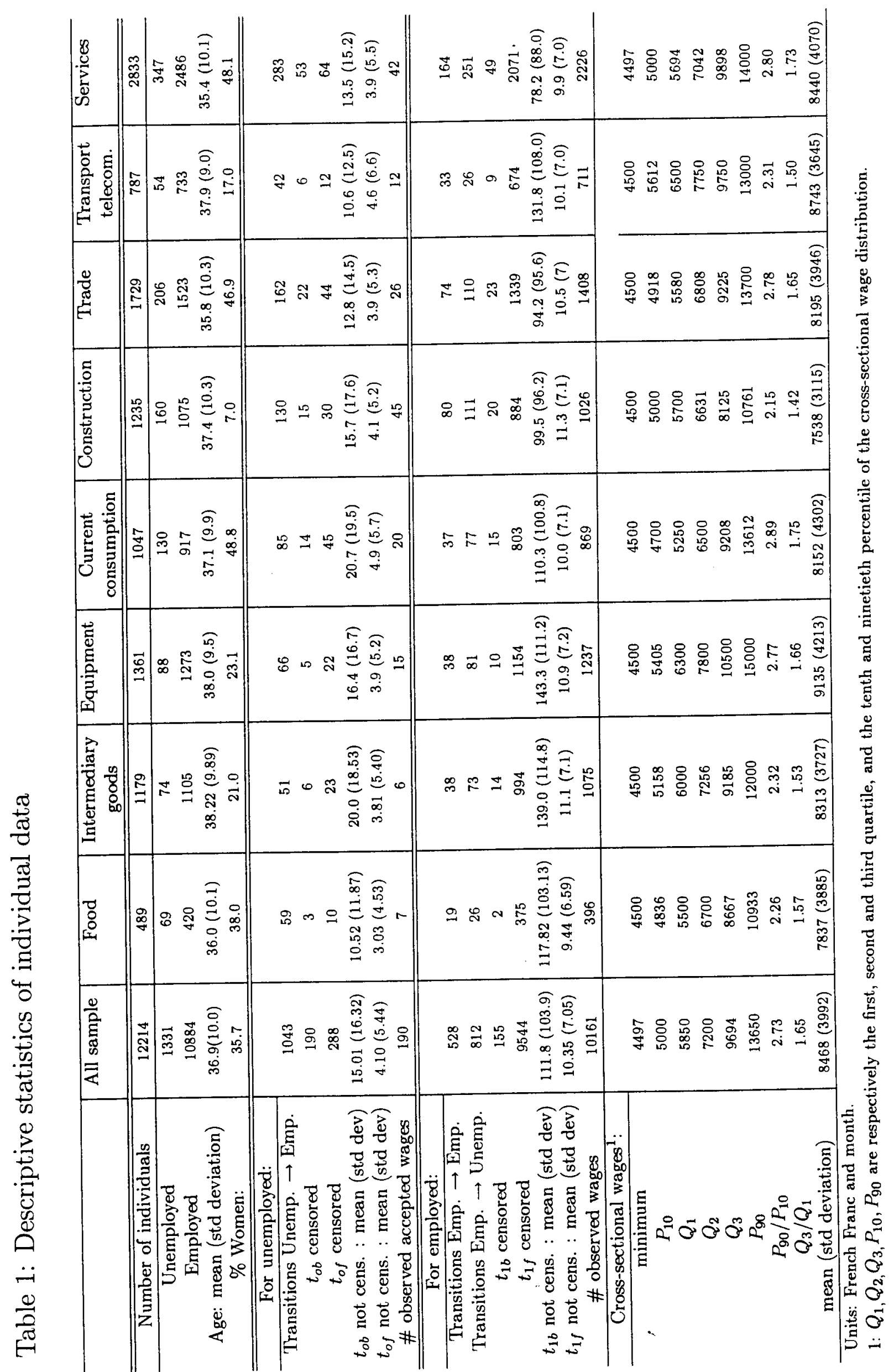


Table 2: Estimation results for the frictional parameters

\begin{tabular}{|c|c|c|c|}
\hline & $1 / \delta$ & $1 / \lambda_{0}$ & $1 / \lambda_{1}$ \\
\hline \multirow[t]{2}{*}{ All sample } & 162.7 & $\overline{15.8}$ & $\overline{125.9}$ \\
\hline & {$[159.6,166.7]$} & {$[15.2,16.5]$} & {$[116.8,135.5]$} \\
\hline \multirow{2}{*}{ Food } & 157.2 & 12.5 & 163.0 \\
\hline & {$[141.1,179.9]$} & {$[10.0,15.2]$} & {$[98.7,245.8]$} \\
\hline Intermediary goods & $\begin{array}{c}207.0 \\
{[196.5, \quad 227.4]}\end{array}$ & $\begin{array}{c}16.5 \\
{[13.9,19.5]}\end{array}$ & $\begin{array}{c}162.5 \\
{[116.4, \quad 194.2]}\end{array}$ \\
\hline \multirow[t]{2}{*}{ Equipment } & 206.6 & 14.6 & 174.2 \\
\hline & {$\left[\begin{array}{ll}194.7, & 223.3\end{array}\right]$} & {$\left[\begin{array}{ll}12.3,17.1 \\
20.8\end{array}\right]$} & {$[128.3,214.6]$} \\
\hline Current consumption & $\begin{array}{c}153.2 \\
{[143.4, \quad 166.6]}\end{array}$ & {$[17.9,23.5]$} & $\begin{array}{c}199.9 \\
{[146.7, \quad 270.7]}\end{array}$ \\
\hline \multirow[t]{2}{*}{ Construction } & 132.5 & 15.3 & 137.8 \\
\hline & $\begin{array}{c}{[126.5, \quad 14} \\
136.0\end{array}$ & $\begin{array}{c}{\left[\begin{array}{cc}13.5, & 17.6\end{array}\right]} \\
14.2\end{array}$ & 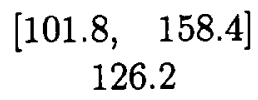 \\
\hline Trade & {$[128.8,147.1]$} & {$[12.6,15.9]$} & {$[95.9, \quad 149.8]$} \\
\hline Transport & $\begin{array}{c}215.4 \\
{[204.6, \quad 244.4]}\end{array}$ & $\begin{array}{c}13.1 \\
{[10.3, \quad 16.7]}\end{array}$ & $\begin{array}{c}86.5 \\
{[49.5,96.7]}\end{array}$ \\
\hline \multirow[t]{2}{*}{ Services } & 115.7 & 13.7 & 82.4 \\
\hline & {$[111.5,123.6]$} & {$[12.6,15.2]$} & 92.9] \\
\hline
\end{tabular}

Time unit: month. In square brackets: the $2.5 \%$ and $97.5 \%$ percentiles of the bootstrap distribution.

Table 3: Properties of the estimated productivity distribution

\begin{tabular}{l|cccccccc}
\hline & $\min$ & $P_{10}$ & $Q_{1}$ & $Q_{2}$ & $Q_{3}$ & $P_{90}$ & $\frac{P_{90}}{P_{10}}$ & $\frac{Q_{3}}{Q_{1}}$ \\
\hline \hline All sample & 6549 & 6891 & 7582 & 9021 & 12770 & 24340 & 3.32 & 1.68 \\
Food & 7056 & 7218 & 7973 & 9632 & 13440 & 20917 & 2.89 & 1.68 \\
Intermediary goods & 6792 & 7262 & 7920 & 9485 & 12287 & 19719 & 2.71 & 1.55 \\
Equipment & 7569 & 8092 & 8904 & 10616 & 14431 & 28487 & 3.52 & 1.62 \\
Current consumption & 7393 & 7565 & 8383 & 10217 & 16924 & 37089 & 4.90 & 2.01 \\
Construction & 6943 & 7318 & 8007 & 9386 & 11907 & 20320 & 2.77 & 1.48 \\
Trade & 6716 & 7090 & 7658 & 9377 & 13302 & 30436 & 4.29 & 1.73 \\
Transport & 6034 & 6528 & 7141 & 8296 & 10389 & 14719 & 2.25 & 1.45 \\
Services & 6267 & 6564 & 7147 & 8844 & 12424 & 23690 & 3.60 & 1.73 \\
\hline
\end{tabular}

Units: French Franc and month. $P_{10}, Q_{1}, \ldots$ denote percentiles and quartiles. 


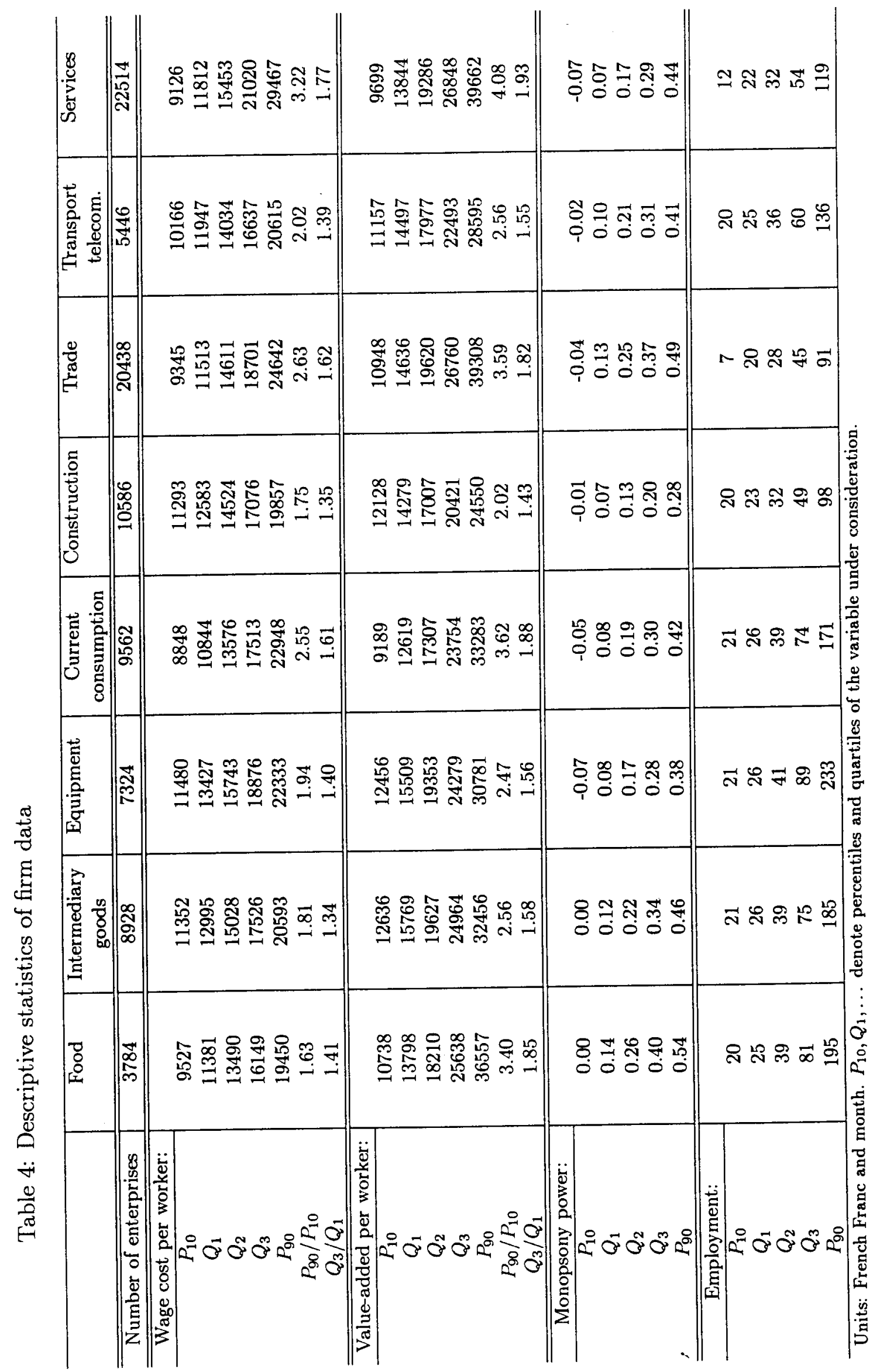


delta $=.0025, k 0=20, k 1=3.5, p \operatorname{pmin0}=6000, \mathrm{~b}=1500$
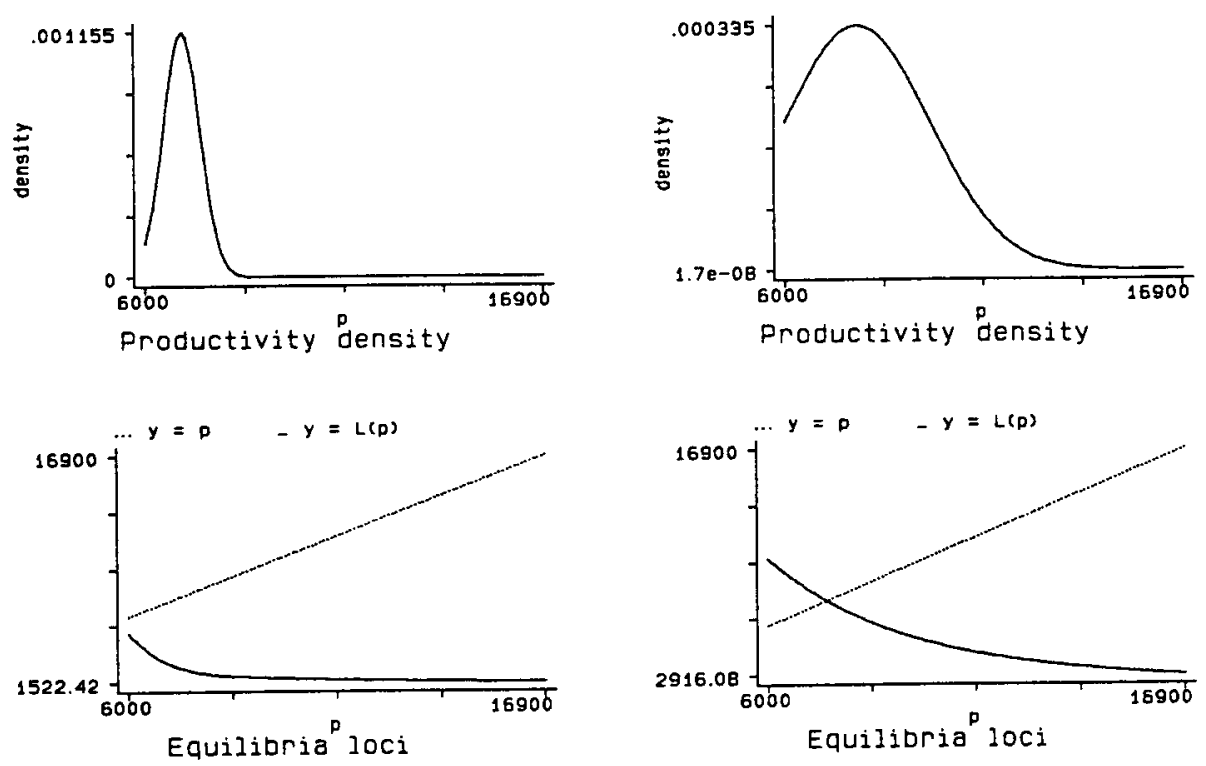

With pmin = pmino

With pmin > pmino

Fig. 1: Unique Equilibrium

Fig. 2: Unique Equilibrium
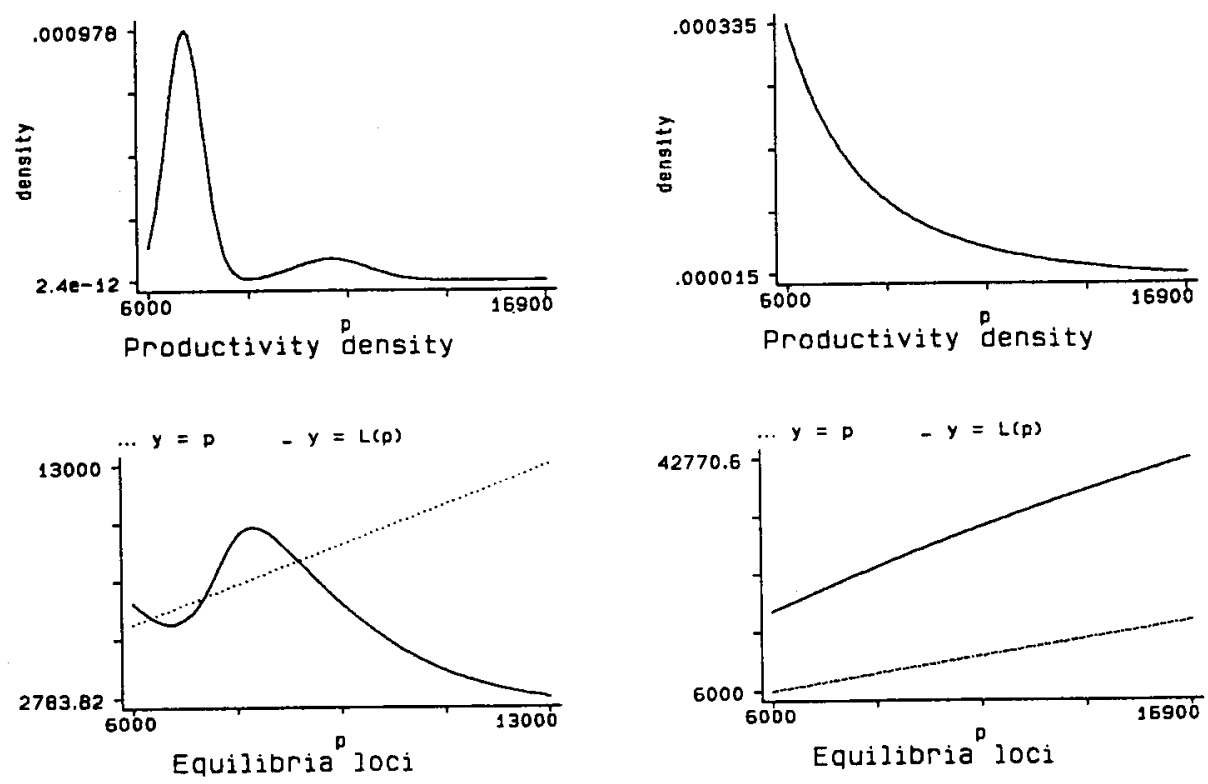

Fig. 3: Multiple Equilibria Fig. 4: No Equilibrium 

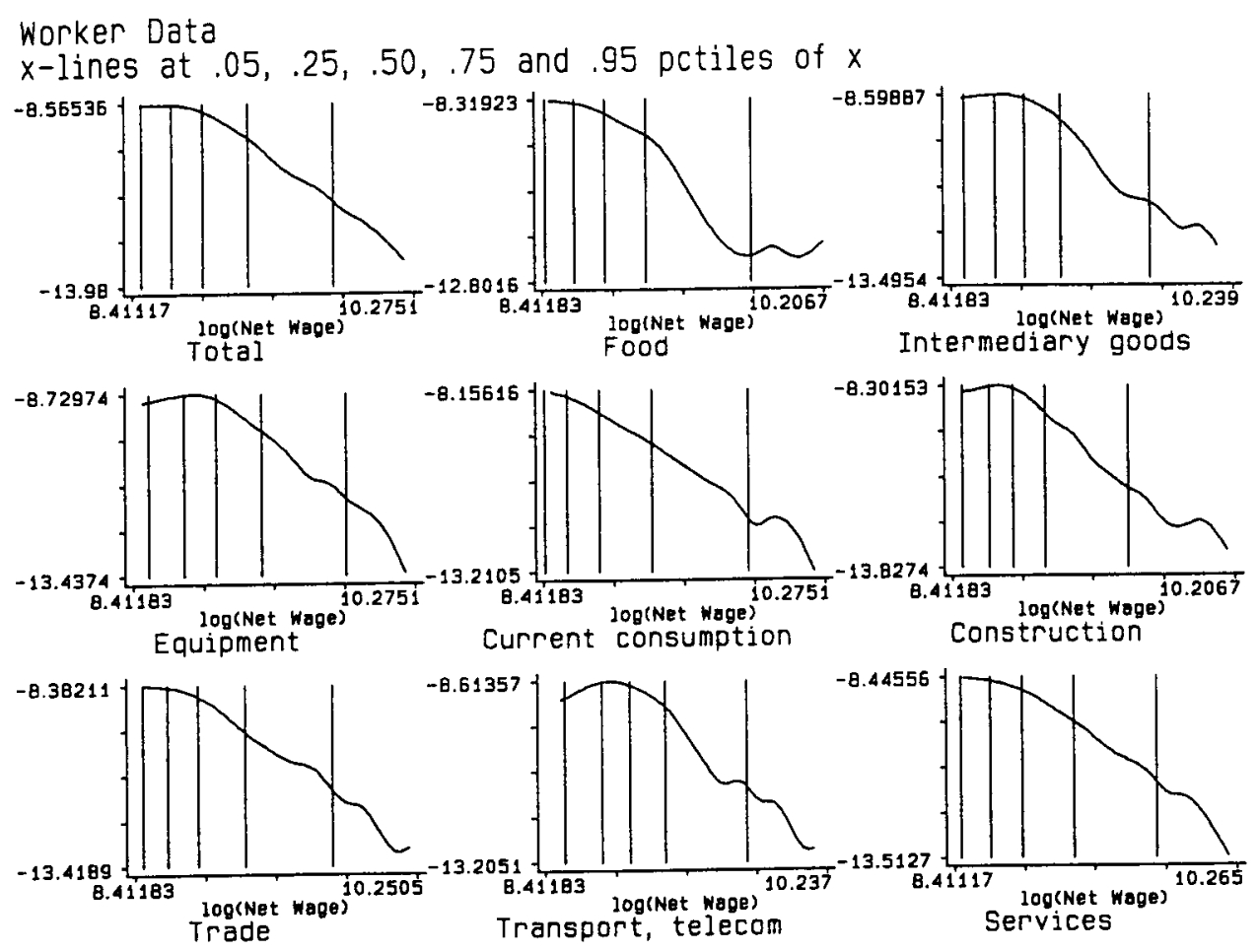

Fig. 5: Earnings Log-Density

Worker Data

$x$-lines at $.05, .25, .50, .75$ and .95 pctiles of $x$
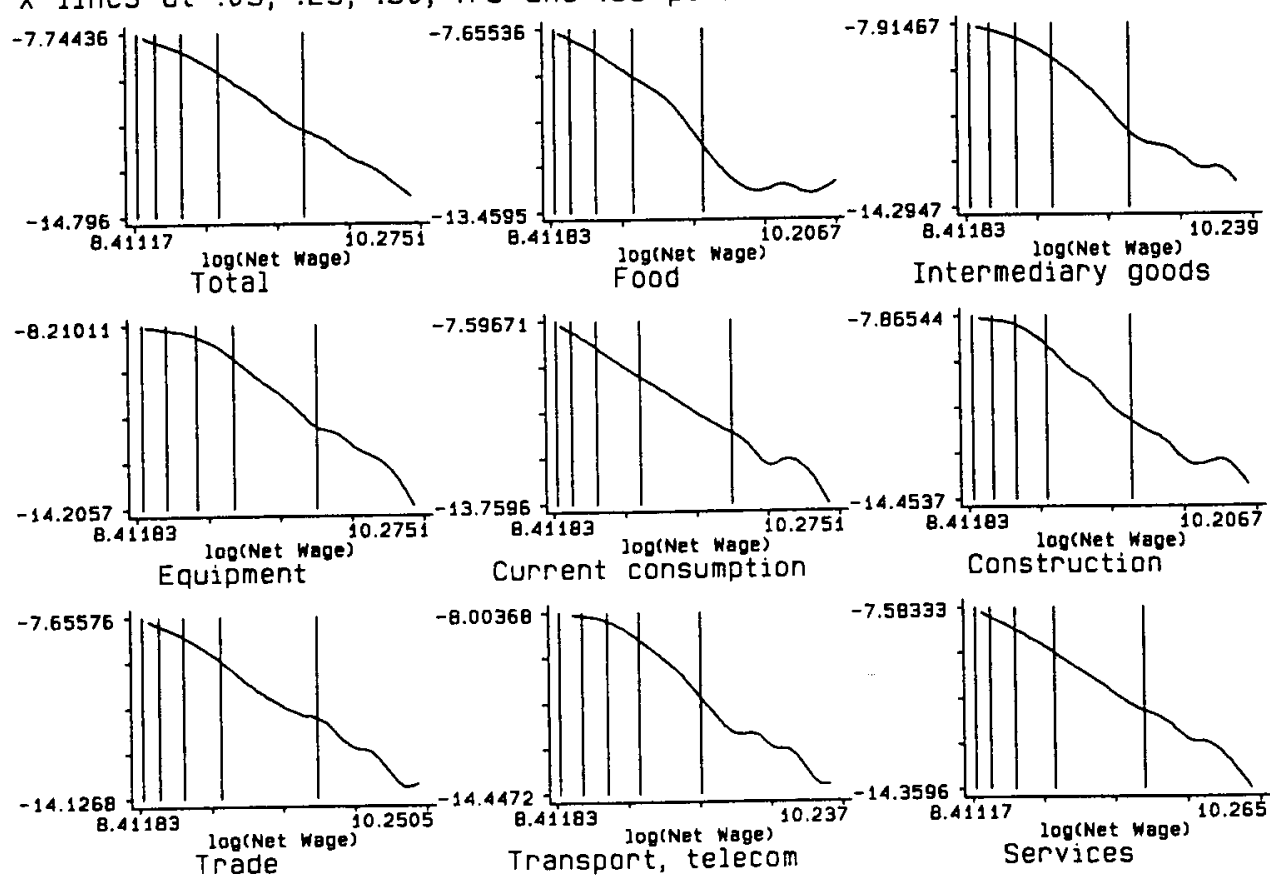

Fig. 6: Wage Offer Log-Density 

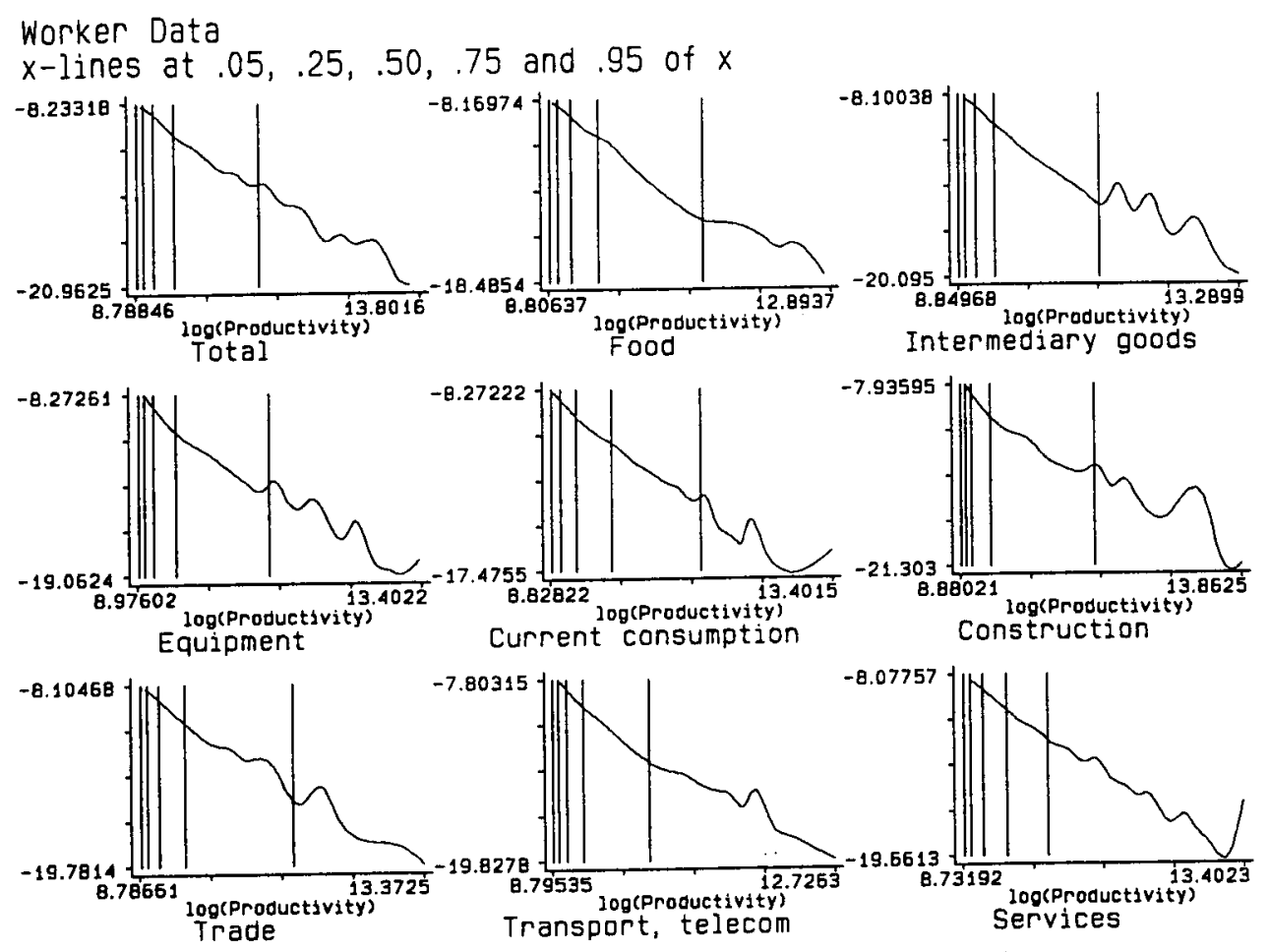

Fig. 7: Productivity Log-Density

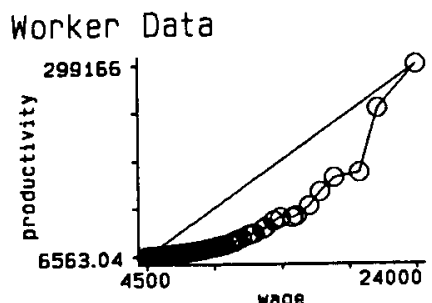

All industries
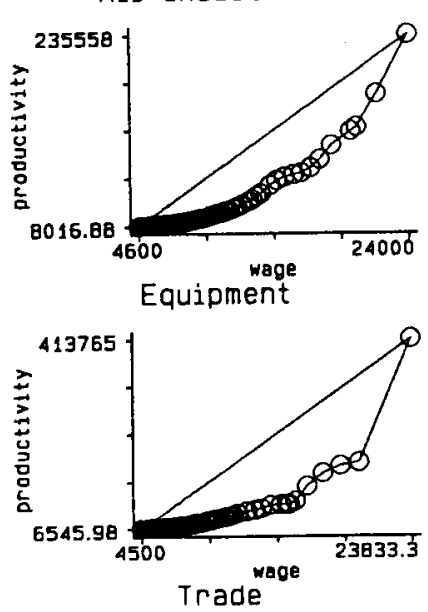
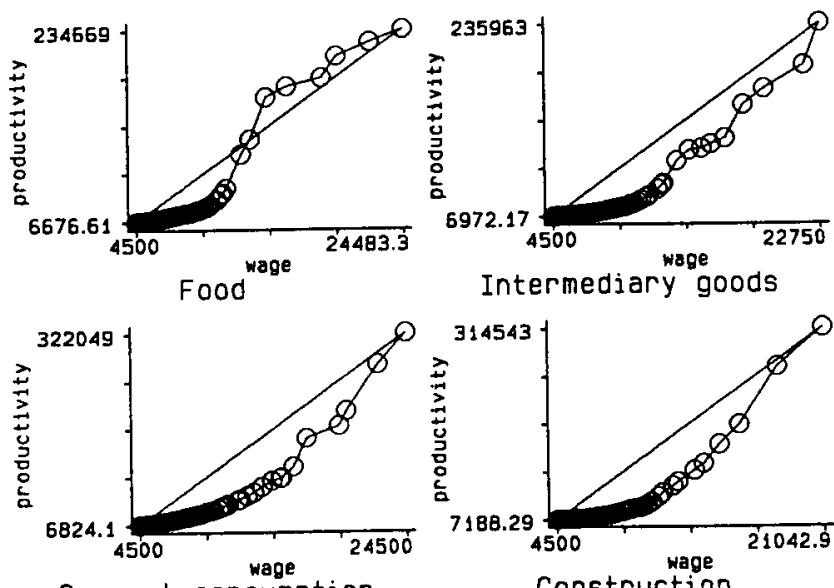

Current consumption

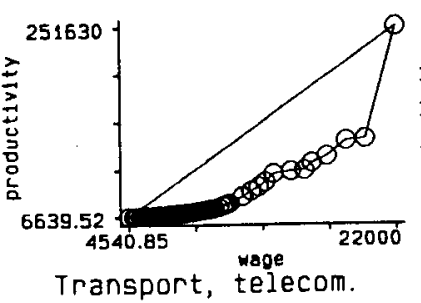

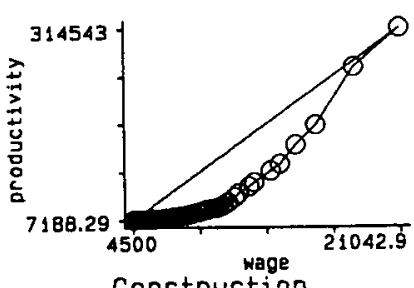

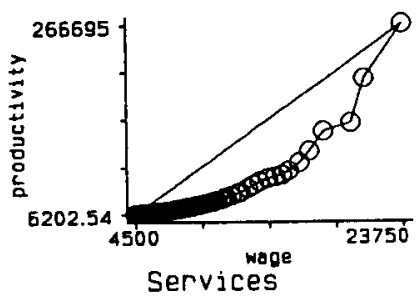

Fig. 8: Pctile-plots of Productivity vs Wage 
Worker Data

$x$-lines at $.05, .25, .50, .75$ and .95 pctiles of $x$
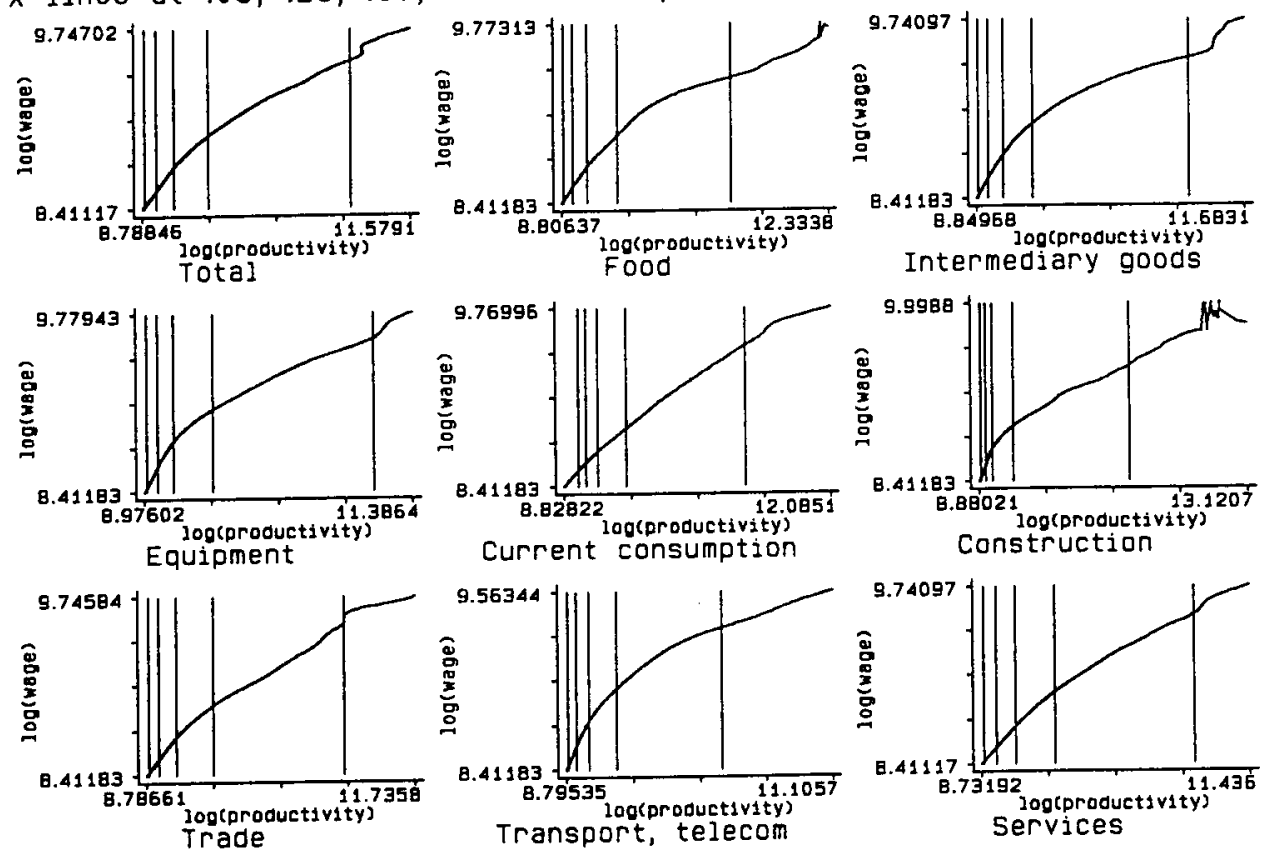

upper $2.5 \%$ values of $\log$ (prod.) trimmed

Fig. 9: Log-Wage vs Log-Productivity

$x$-line at $.05, .25, .50, .75$ and .95 pctiles of $x$

$y$-lines at minimum, .75 and .95 pctiles of profit rates
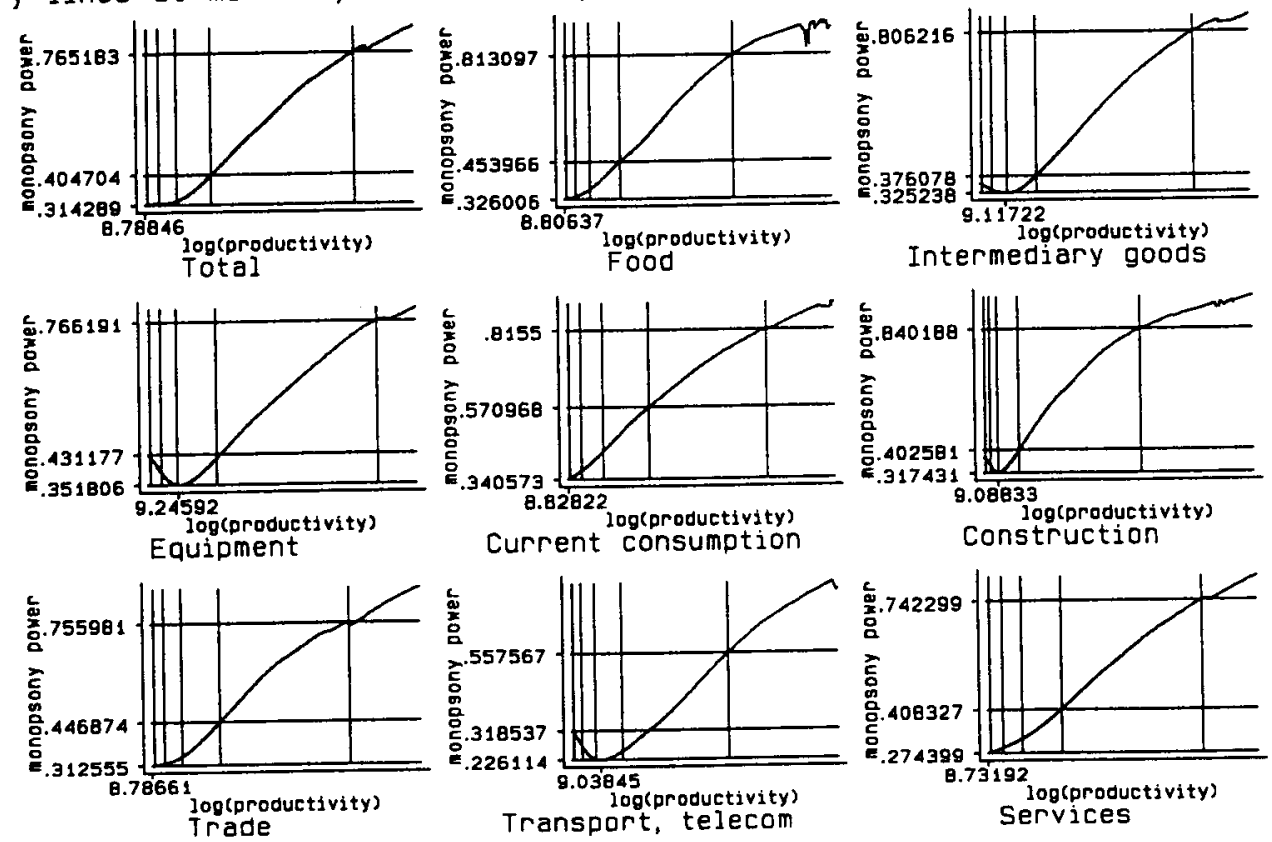

upper $2.5 \%$ of productivities trimmed

Fig. 10: Monopsony Power vs Log Productivity in Worker Data 
Firm Data
$x$-lines at $.05, .25, .50, .75$ and .95 pctiles of $x$
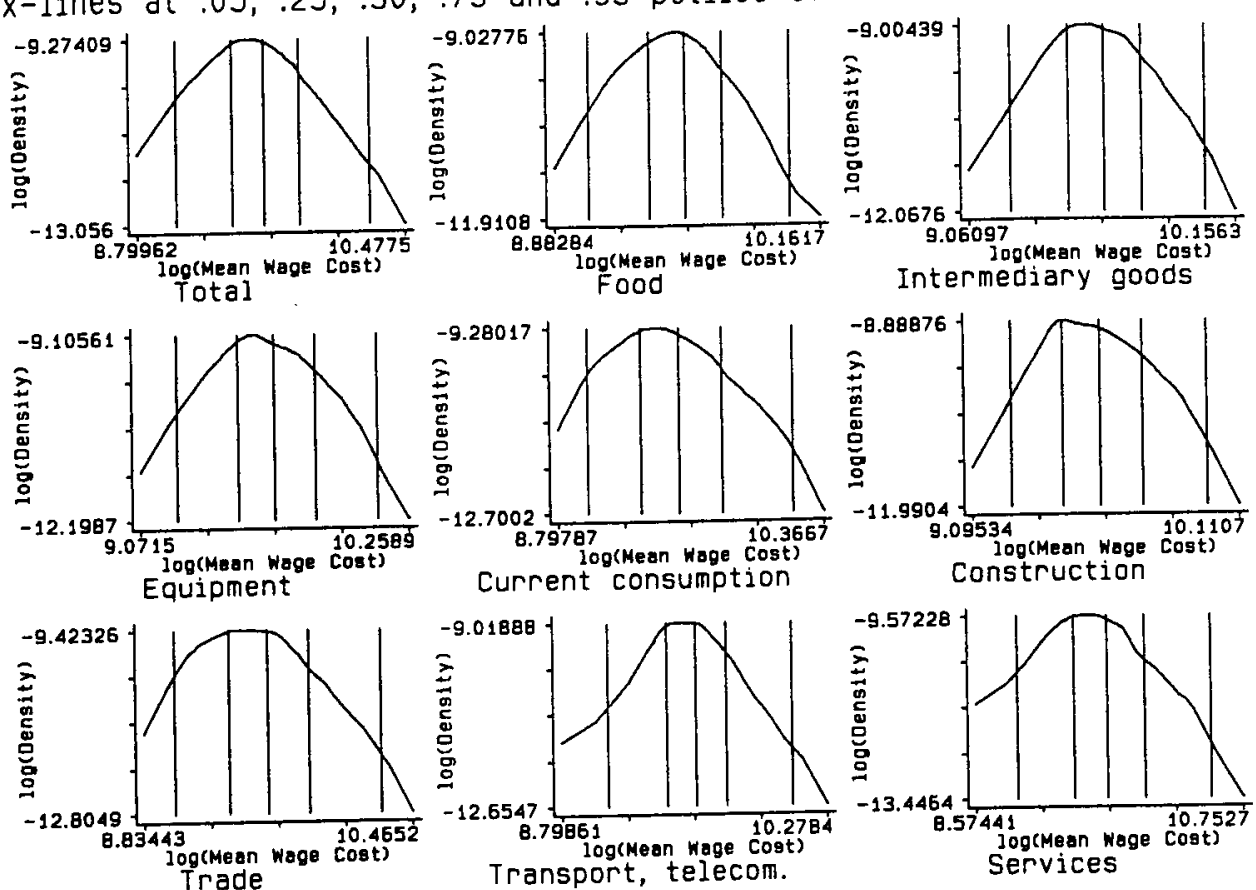

Fig. 11: Mean Wage Cost Density

Firm Data

$x$-lines at $.05, .25, .5, .75$ and .95 pctiles of $x$
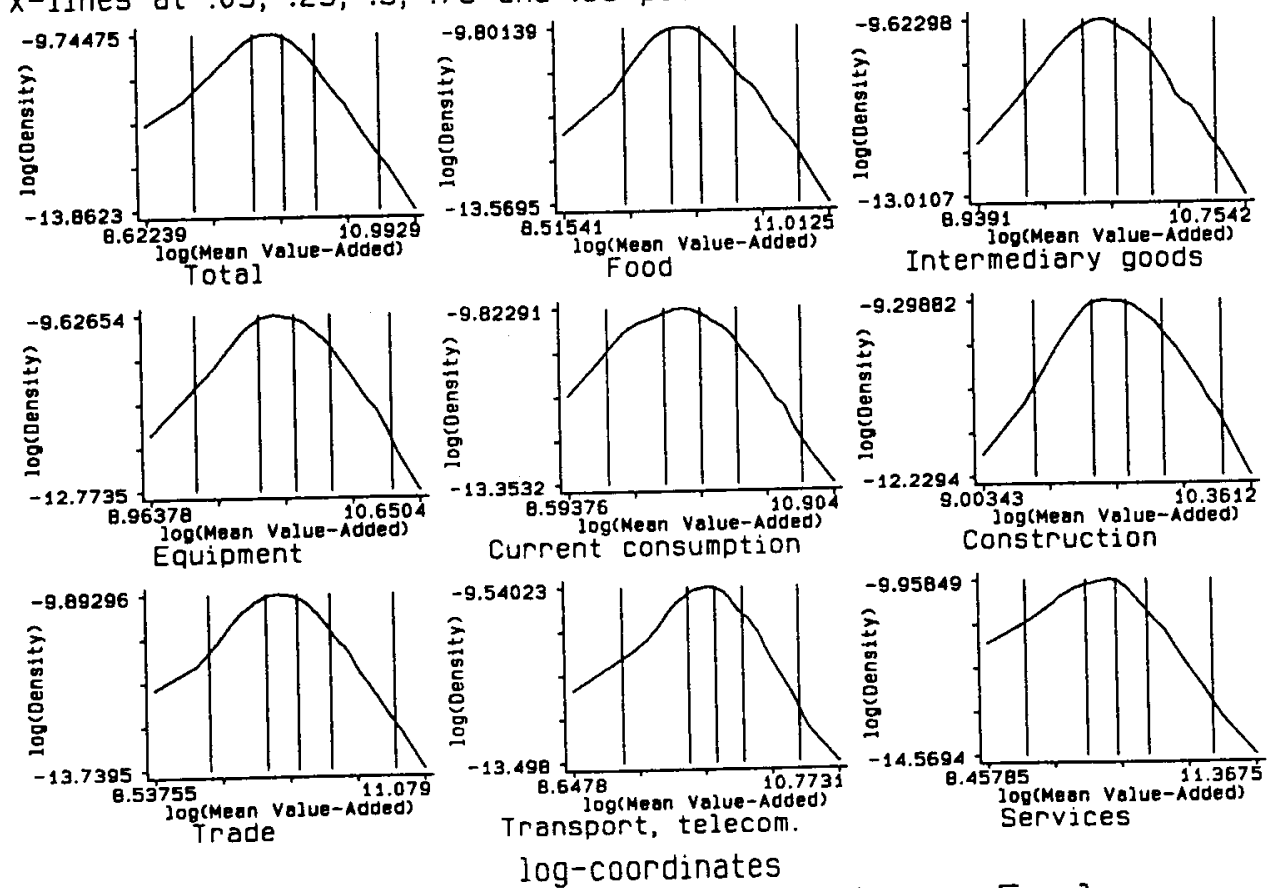

Fig. 12: Density of Value-Added per Employee 

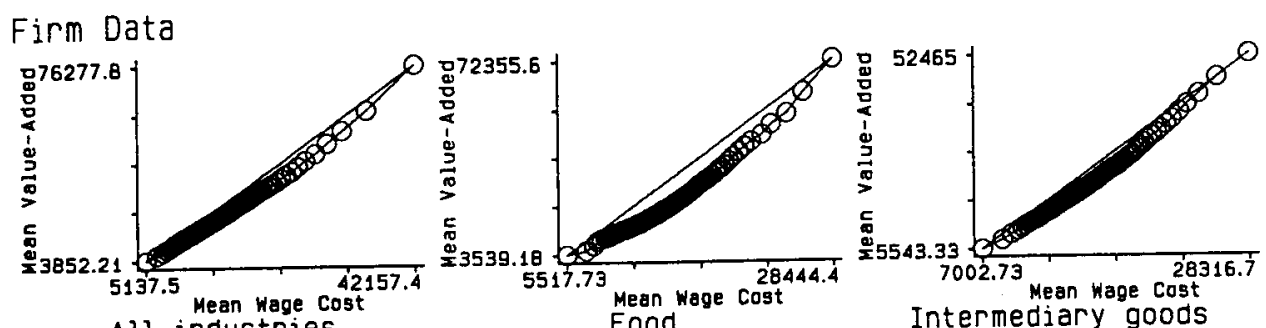
All industries
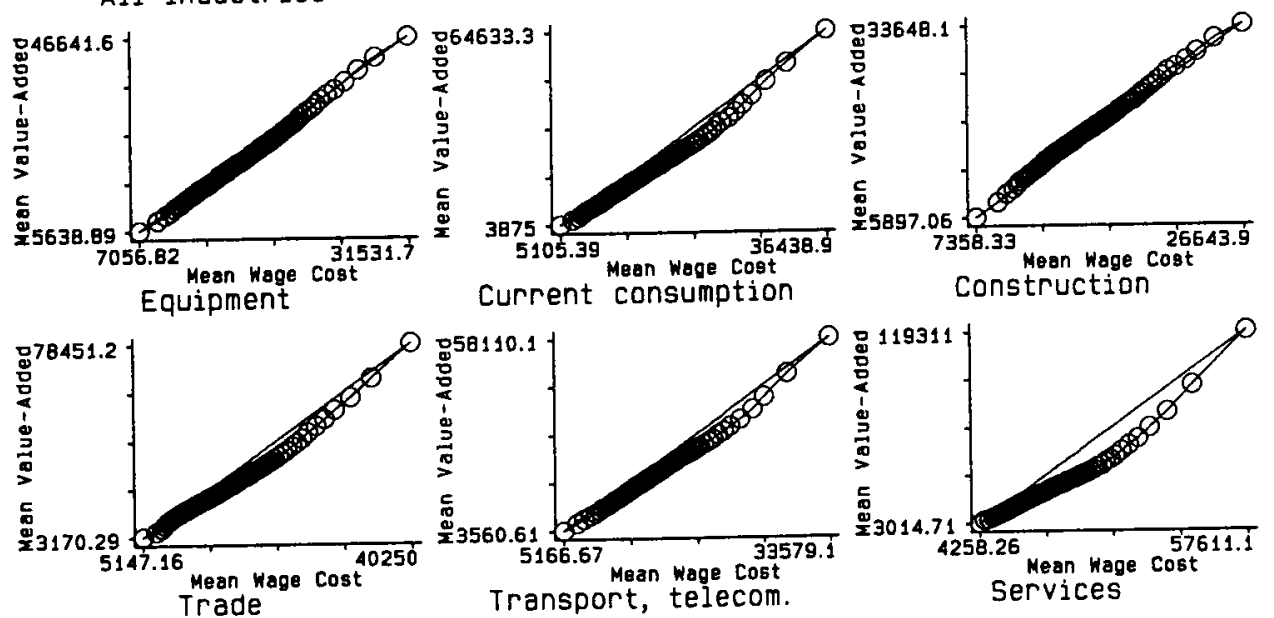

Fig. 13. Pctile-plots of VA per Employee vs Mean Wage Cost 
$x$-lines at $.05, .25, .5, .75, .95$ pctiles of $x$ $y$-lines at $.05, .25, .5, .75, .95$ pctiles of $y$

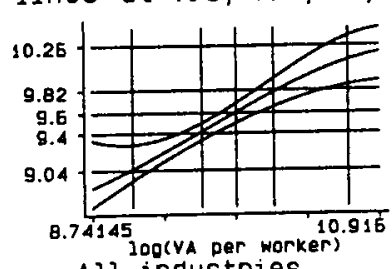

All industries
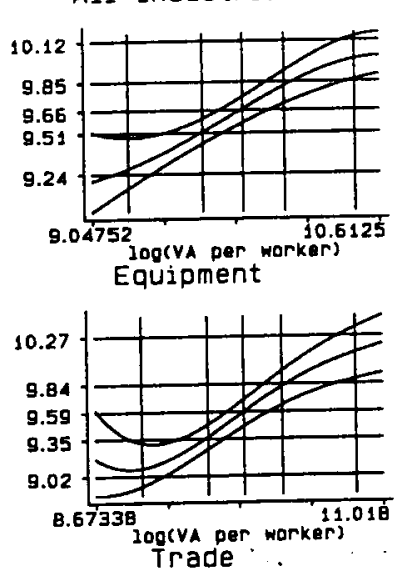
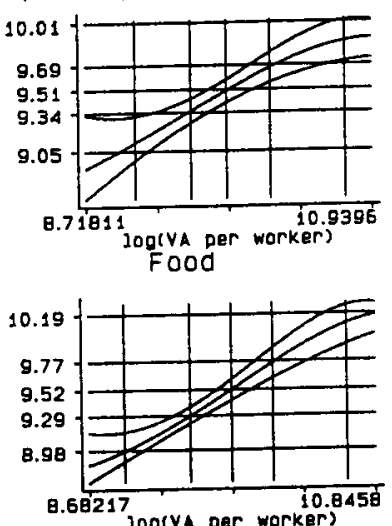
Current consumption

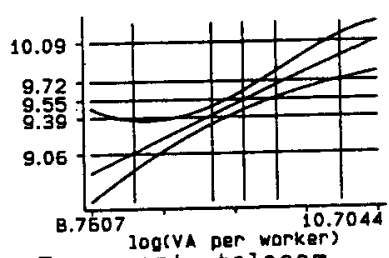

log(va per worker)
Transport, telecom.

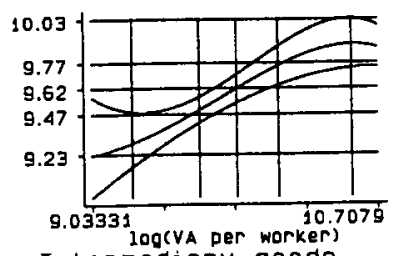

Intermediary goods

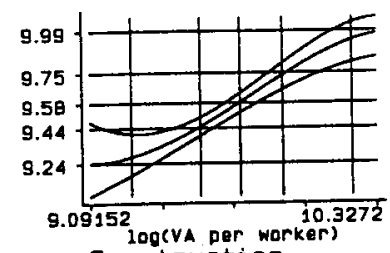

Construction

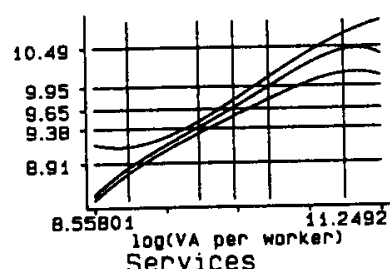
Services

\section{5\% upper and lower values of $x$ trimmed}

Fig. 14: Quantile Regressions of Log Mean wage Cost

$x$-lines at $.05, .25, .5, .75, .95$ pctiles of $x$ $y$-lines at $.05, .25, .5, .75, .95$ pctiles of $y$

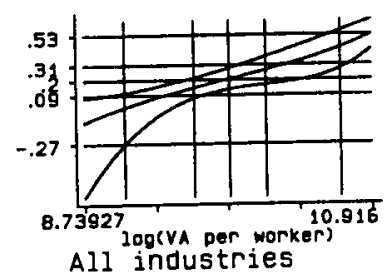
All industries
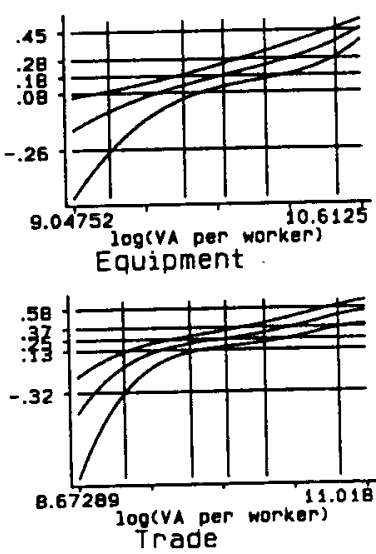

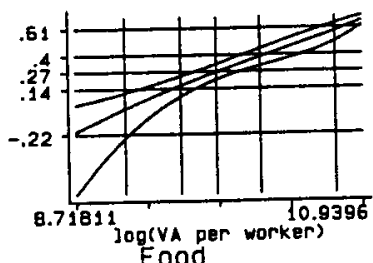
Food

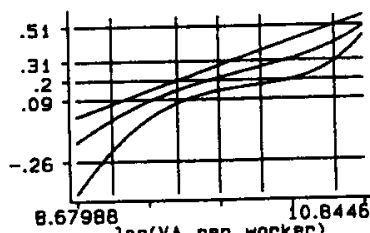
Current consumption

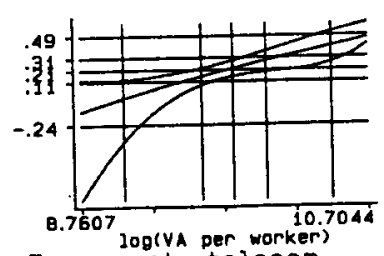

$\log (v a$ per worker)
Transport, telecom.

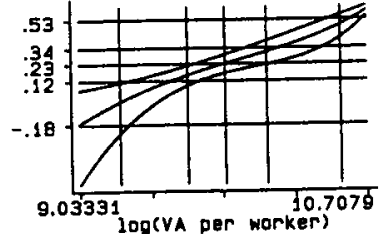

Intermediary goods

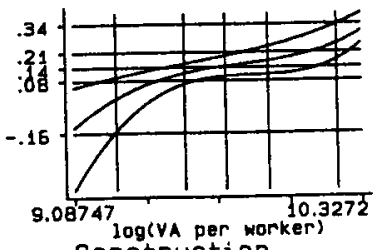
Construction

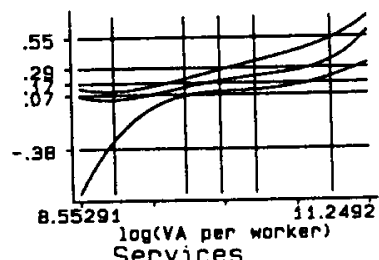
Services

2.5\% upper and lower values of $x$ trimmed

Fig. 15: Quantile Regressions of Profit Shares on Firm Data 
$x$-lines at $.05, .25, .5, .75, .95$ pctiles of $x$

$y$-lines at $.05, .25, .5, .75, .95$ pctiles of $y$
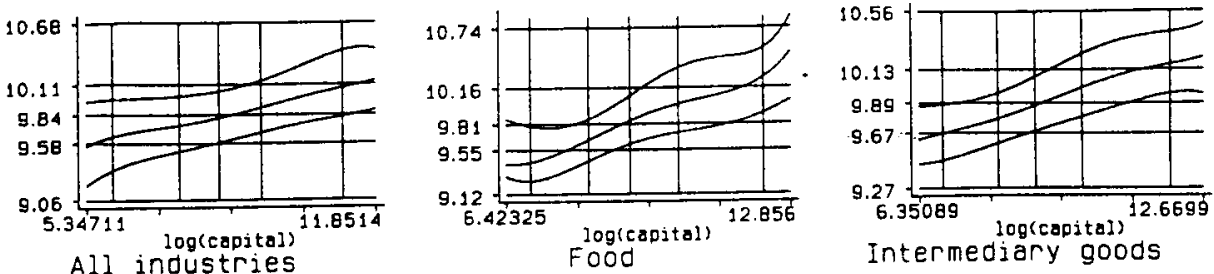

Intermediany goods
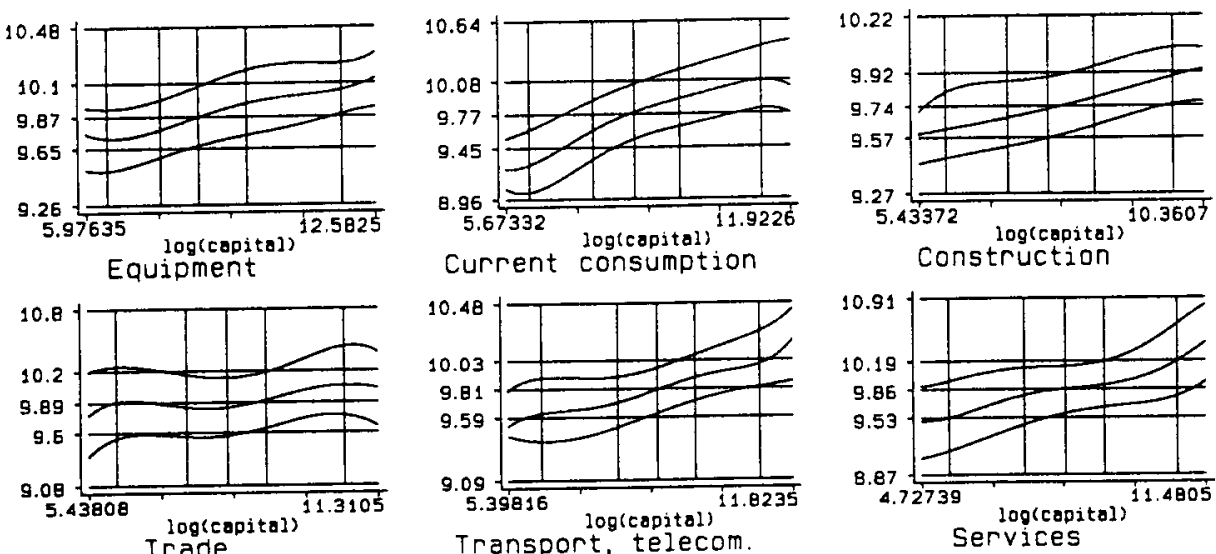

2.5\% upper and lower values of $x$ trimmed - Firm Data

Fig. 16: Quantile Regressions of Mean VA on Gross Capital

$x$-lines at $.05, .25, .5, .75, .90$ pctiles of $x$ $y$-lines at $.05, .25, .5, .75, .90$ pctiles of $y$

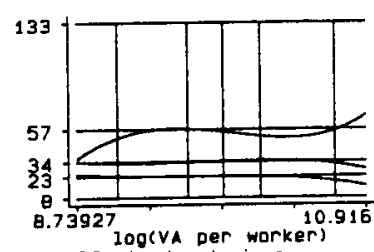
All industries
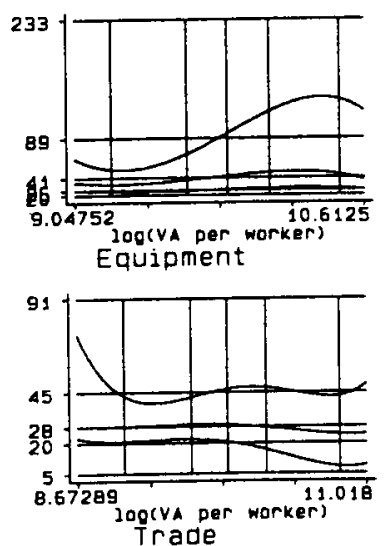

2.5\% upper and lower values of $x$ trimmed $\log (v a$ per worker)
Current consumption

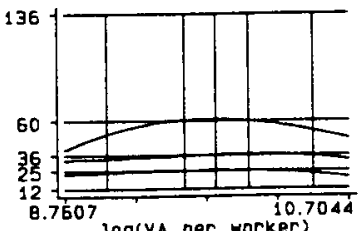

Q.760 $\log (v a$ per warker)

Transport, telecom.

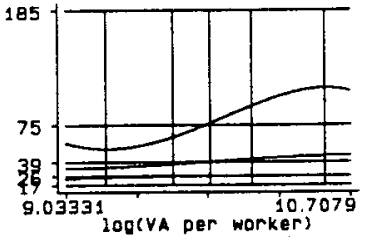

Intermediary goods

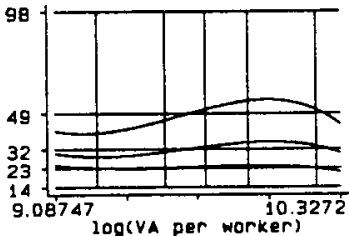
Construction

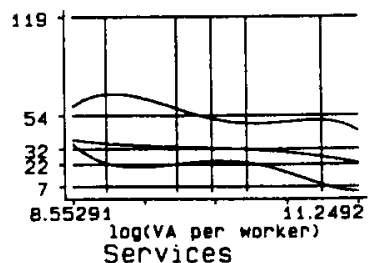


Working

Paper

95-01 Christian Belzil: Contiguous Duration Dependence and Nonstationarity in Job Search

95-02 Christian Belzil: Unemployment Insurance and Unemployment Over Time: An Analysis with Event History Data.

95-03 Christian Belzil: Unemployment Duration Stigma and Reemployment Earnings.

95-04 Christian Belzil: Relative Efficiencies and Comparative Advantages in Job Search.

95-05 Niels Henning Bjørn: Causes and Consequences of Persistent Unemployment.

95-06 Nicholas M. Kiefer and Mark F.J. Steel: Bayesian Analysis of the Prototypal Search Model.

95-07 Nicholas M. Kiefer, Ranjini Natarajan and Charles E. McCulloch: Maximum Likelihood for the Multinomial Probit Model.

95-08 Christian Belzil and Philip Hergel: Fertility and the Human Capital Loss of Non-Participation

95-09 Christian Belzil, William A. Sims and Philip Hergel: Endogeneity, Self-Selectivity and the Sensitivity of Female Earnings to Non-Participation.

95-10 Paul Bingley, Niels Henning Bjørn and Niels Westergård-Nielsen: Wage Mobility in Denmark 1980-1990.

95-11 Audra J. Bowlus, Nicholas M. Kiefer and George R Neumann: Estimation of Equilibrium Wage Distributions with Heterogeneity.

95-12 Anders Björklund and Tor Eriksson: Unemployment and Mental Health: Evidence from Research in the Nordic Countries 
Working

Paper

95-13 Melvyn G. Coles and John G. Treble: Here Today, Gone Tomorrow: Calculating the Price of Worker Reliability.

95-14 Christian Belzil: Employment Reallocation, the Return to Human Capital and the Allocation of Workers Between Expanding and Declining Firms.

95-15 John T. Addison and Jean-Luc Grosso: Job Security Provisions and Employment: Revised Estimates.

95-16 John T. Addison and McKinley L. Blackburn: A Puzzling Aspect of the Effect of Advance Notice on Unemployment.

95-17 Peder J. Pedersen and Nina Smith: The Welfare State and the Labour Market.

95-18 Mette Lausten: Inter-Industry Wage Differentials in Denmark ?

96-01 Mark Yuying An: Log-concave Probability Distributions: Theory and Statistical Testing.

96-02 Audra Bowlus, Nicholas M. Kiefer and George R. Neumann: Fitting Equilibrium Search Models to Labour Market Data.

96-03 Karsten Albæk, Mahmood Arai, Rita Asplund, Erling Barth and Erik Strøyer Madsen: Employer Size-Wage Effects in the Nordic Countries.

96-04 Bent J. Christensen and Nicholas M. Kiefer: Inference in Non-Linear Panels with Partially Missing Observations: The Case of the Equilibrium Search Model.

96-05 Michèle Naur and Nina Smith: Cohort Effects on the Gender Wage Gap in Denmark.

96-06 Elizabeth J. Cunningham: The Relationship between Recruiting and Screening within the Employer Search Framework

96-07 Tim Barmby and Nina Smith: Household Labour Supply in Britain and Denmark: Some Interpretations Using a Model of Pareto Optimal Behaviour.

96-08 Michael Rosholm: Unemployment Duration over the Business Cycle.

96-09 Mark Yuying An and Ming Liu: Structural Analysis of Labor Market Transitions Using Indirect Inference 
Working

Paper

96-10 Paul Bingley and Niels Westergård-Nielsen: Worker and Plant Wages: Estimates from a Multi-Level Model

96-11 Paul Bingley and Gauthier Lanot: Danish Private Sector Wage Policies and Male Retirement Decisions

96-12 George R. Neumann and Gauthier Lanot: Measuring Productivity Differences in Equilibrium Search Models.

96-13 Tor Eriksson: Executive Compensation and Tournament Theory: Empirical Tests on Danish Data.

96-14 Peter Jensen and Helena Skyt Nielsen: Child Labour or School Attendance? Evidence from Zambia.

96-15 Ebbe Krogh Graversen: Male and Female Labour Supply in Denmark.

96-16 Tor Eriksson and Markus Jäntti: The Distribution of Earnings in Finland 19711990.

96-17 Ebbe Krogh Graversen: Measuring Labour Supply Responses to Tax Changes by Use of Exogenous Tax Reforms.

97-01 Report $1993-1996$.

97-02 Paul Bingley and Ian Walker: Labour Supply with In-Work and In-Kind Transfers.

97-03 Paul Bingley and Ian Walker: Household Unemployment and the Labour Supply of Married Women.

97-04 Christian Belzil: Job Creation and Destruction, Worker Reallocation and Wages.

97-05 Christian Belzil: The Dynamics of Female Time Allocation upon a First Birth

97-06 Christian Belzil and Jörgen Hansen: Estimating the Returns to Education from a Non-Stationary Dynamic Programming Model

97-07 Niels Westergård-Nielsen and Anders Rue Rasmussen: Apprenticeship Training in Denmark - the impacts of subsidies. 
97-08 H. Bunzel, B.J. Christensen, P. Jensen, N.M. Kiefer, L. Korsholm, L. Muus, G.R. Neumann, M. Rosholm: Specification and Estimation of Equilibrium Search Models.

97-09 Ebbe Krogh Graversen: Work disincentive effects of taxes among Danish married men and women

97-10 Jukka Vittaniemi: Top Executive Compensation and Company Performance in Finland.

97-11 Peder J. Pedersen and Nina Smith: Trends in the Danish Income Distribution, 1976-90.

97-12 Ronald L. Oaxaca and Michael R. Ransom: Identification in Detailed Wage Decompositions

97-13 Bent J. Christensen and Nicholas M. Kiefer: Panel Data, Local Cuts and Orthogeodesic Models

97-14 Michael Rosholm: The risk of marginalization in the labour market: Application of a three state dependent competing risks duration model.

97-15 Helena Skyt Nielsen and Michael Rosholm: The Incidence of Unemployment: Identifying Quits and Layoffs

97-16 Tor Eriksson: Long-Term Earnings Mobility of Low-Paid Workers

97-17 Lars Korsholm: The Semiparametric Normal Variance-Mean Mixture Model

98-01 Helena Skyt Nielsen: Two Notes on Discrimination and Decomposition

98-02 Esben Agerbo, Tor Eriksson, Preben Bo Mortensen and Niels Westergård-Nielsen: Unemployment and mental disorders - an empirical analysis

98-03 Birthe Larsen: Minimum Wages, Technological Progress and Loss of Skill

98-04 Kevin T. Reilly and Tony S. Wirjanto: Does More Mean Less ? The Male/Female Wage Gap and the Proportion of Females at the Establishment Level

98-05 Helena Skyt Nielsen: Low Demand for Primary Education: Traditions or Economic Incentives?

98-06 Ebbe Krogh Graversen and Nina Smith: Labour supply, overtime work and taxation in Denmark 
98-07 Christian Bontemps, Jean-Marc Robin, and Gerard J. van den Berg: Equilibrium Search with Continuous Productivity Dispersion: Theory and Non-Parametric Estimation. 
ISSN 0908-8962

CENTRE FOR LABOUR MARKET AND SOCIAL RESEARCH Science Park Aarhus, Gustav Wieds Vej 10C, 8000 Aarhus C, Denmark Phone: $+4589422350 \quad$ Fax: $+4589422365 \quad$ Email: cls@cls.dk WWW: http://www.cls.dk 